Research Article

\title{
Cytological and genome size data analyzed in a phylogenetic frame: Evolutionary implications concerning Sisyrinchium taxa (Iridaceae: Iridoideae)
}

Paula Burchardt ${ }^{1}$, Tatiana T. Souza-Chies ${ }^{1,2}$, Olivier Chauveau ${ }^{3}$, Sidia M. Callegari-Jacques ${ }^{1,4}$, Lauís Brisolara-Corrêa ${ }^{1}$, Camila Dellanhese Inácio ${ }^{3}$, Lilian Eggers ${ }^{2,3}$, Sonja Siljak-Yakovlev ${ }^{5}$, José Marcello Salabert de Campos ${ }^{6}$ and Eliane Kaltchuk-Santos ${ }^{1,7}$

${ }^{1}$ Programa de Pós-Graduação em Genética e Biologia Molecular, Universidade Federal do Rio Grande do Sul, Porto Alegre, RS, Brazil.

${ }^{2}$ Departamento de Botânica, Instituto de Biociências, Universidade Federal do Rio Grande do Sul, Porto Alegre, RS, Brazil.

${ }^{3}$ Programa de Pós-Graduação em Botânica, Instituto de Biociências, Universidade Federal do Rio Grande do Sul, Porto Alegre, RS, Brazil.

${ }^{4}$ Departamento de Estatística, Instituto de Matemática e Estatística, Universidade Federal do Rio Grande do Sul, Porto Alegre, RS, Brazil.

${ }^{5}$ Ecologie Systématique Evolution, Université Paris-Sud, CNRS, AgroParisTech, Orsay, France.

${ }^{6}$ Departamento de Biologia, Instituto de Ciências Biológicas, Universidade Federal de Juiz de Fora, Juiz de Fora, MG, Brazil.

${ }^{7}$ Departamento de Genética, Instituto de Biociências, Universidade Federal do Rio Grande do Sul, Porto Alegre, RS, Brazil.

\begin{abstract}
Sisyrinchium is the largest genus of Iridaceae in the Americas and has the greatest amount of cytological data available. This study aimed at investigating how genomes evolved in this genus. Chromosome number, genome size and altitude from species of sect. Viperella were analyzed in a phylogenetic context. Meiotic and pollen analyses were performed to assess reproductive success of natural populations, especially from those polyploid taxa. Character optimizations revealed that the common ancestor of sect. Viperella was probably diploid $(2 n=2 x=18)$ with two subsequent polyplodization events. Total DNA content $(2 \mathrm{C})$ varied considerably across the phylogeny with larger genomes detected mainly in polyploid species. Altitude also varied across the phylogeny, however no significant relationship was found between DNA content changes and altitude in our data set. All taxa presented regular meiosis and pollen viability (> $87 \%$ ), except for S. sp. nov. aff. alatum (22.70\%), suggesting a recent hybrid origin. Chromosome number is mostly constant within this section and polyploidy is the only source of modification. Although $2 \mathrm{C}$ varied considerably among the 20 taxa investigated, the diversity observed cannot be attributed only to polyploidy events because large variations of DNA content were also observed among diploids.
\end{abstract}

Keywords: Ancestral chromosome number, DNA content, meiotic behavior, pollen viability, polyploidy.

Received: March 15, 2017; Accepted: August 24, 2017.

\section{Introduction}

Iridaceae is one of the largest Asparagales families (APG IV, 2016), and chromosome number was determined for about $50 \%$ of the 2030 species included, although mostly for taxa from the Northern Hemisphere and Africa (Goldblatt and Takei, 1997). Knowledge about cytological

Send correspondence to Eliane Kaltchuk dos Santos. Programa de Pós-Graduação em Genética e Biologia Molecular, Prédio 43312, Universidade Federal do Rio Grande do Sul, Avenida Bento Gonçalves 9500, 91501-970 Porto Alegre, RS, Brazil. E-mail: eliane.kaltchuk@ufrgs.br. characters has been especially helpful for genera circumscription and to understand species relationship in various genera (Goldblatt and Takei, 1997). In this family, there is great karyological variation, comprising karyotype features, basic chromosome number $(x)$ and ploidy level. Chromosome heteromorphism and asymmetry are frequently found in several species (Alves et al., 2011). Such karyotypic variations are especially related to polyploidy and descending disploidy, both considered important events for the diversification of subfamily Iridoideae (Goldblatt and Takei, 1997; Moraes et al., 2015). 
Sisyrinchium L. is the largest genus of Iridaceae in the Americas (Goldblatt and Manning, 2008) and presents a large amount of cytological data, mainly for North American species (Kenton and Heywood, 1984; Kenton et al., 1986; Goldblatt and Takei, 1997). According to the literature, the ancestral basic chromosome number for Sisyrinchium is probably $x=9$ (Goldblatt and Manning, 2008; Chauveau et al., 2011), although other base numbers $\left(x_{2}=\right.$ $5,6,8,17$ ) also occur within the genus (Goldblatt and Manning, 2008). All Sisyrinchium species from Brazil studied by Souza-Chies et al. (2012) had a base chromosome number of $x=9$, except Sisyrinchium micranthum Cav. ( $x=8$; Tacuatiá et al., 2012). Typically, Sisyrinchium species have small chromosomes, especially those with $x=$ $8(<1 \mathrm{~mm})$, hindering karyotype establishment (Kenton et al., 1986).

Similarly to other families of Asparagales, such as Amaryllidaceae and Orchidaceae, Iridaceae present considerable variation in genome size (Bennett and Leitch, 2012) even within genera such as Sisyrinchium, the genus with the largest amount of C-value estimates (Goldblatt $e t$ al., 1984; Kenton et al., 1986; Moraes et al., 2015). DNA measurements in Sisyrinchium have shown that DNA contents are generally low, with haploid genomes (C-values) varying between 0.25 and $4.20 \mathrm{pg}$ (Kenton et al., 1986; Moraes et al., 2015).

Phylogenetic trees have been used, traditionally, to identify patterns of chromosome diversification (Moraes et al., 2012; Koehler et al., 2008). More recently, however, statistical analyses, such as ancestral state reconstruction based on maximum likelihood, have enabled studies of karyotype evolution under a phylogenetic perspective (Escudero et al., 2014; Moraes et al., 2015). Moreover, cytological data have been successfully used to help taxonomic decisions within Iridaceae (De Tullio et al., 2008).

Sisyrinchium is taxonomically complex, and a study published recently showed that most of the infrageneric subdivisions recognized for the genus are not monophyletic (Chauveau et al., 2011). This study focused on clade IV of Chauveau et al. (2011), which includes species from South America that belong to two different sections sensu Ravenna: Viperella and Hydastylus in part (Ravenna, 2000, 2002). Thus, in an attempt to provide useful information for future taxonomic studies, cytological data were analyzed in a phylogenetic framework.

Considering the scarce cytological information available for Sisyrinchium species from Southern Brazil and its relevance to understand Iridaceae evolution, new data were obtained in the present study concerning: (1) chromosome number and ploidy level, (2) genome size (GS), (3) meiotic behaviour and meiotic index, as well as (4) pollen viability and morphology. Chromosome numbers and GS were then analyzed in an evolutionary context and the relationship between DNA content and altitude variations was also tested.

\section{Material and Methods}

\section{Taxonomic sampling}

A total of 43 accessions representing 25 Sisyrinchium taxa from clade IV according to Chauveau et al. (2011), hereafter named Viperella-Hydastylus clade, were collected in Brazil from 2006 to 2014. Most species currently recognized in this monophyletic group (see Chauveau et al., 2011) were included in our sampling. All vouchers were deposited in the ICN Herbarium, Instituto de Biociências, Universidade Federal do Rio Grande do Sul, Porto Alegre, RS, Brazil.

Based on Chauveau et al. (2011), two members of the sister sect. Spathirhachis were selected as outgroup. Plant material was obtained from the wild, except one outgroup species (Table 1). Taxa sampled, accession numbers, collection data, voucher information and identifiers of GenBank sequence records are given in Table 1. Twenty-seven DNA samples representing each taxon included in the study were used to infer phylogenetic relationships, whereas ploidy levels and genome size information were obtained for 19 and 20 taxa, respectively (Table 2). Additionally, meiotic analyses were conducted on seven species of the ingroup (Table S1), while pollen viability and morphology were reported for 12 species (Table 3).

\section{Mitotic analysis}

Root tips were pretreated with 8-hydroxyquinoline $(2 \mathrm{mM})$ for $24 \mathrm{~h}$ at $10^{\circ} \mathrm{C}$, fixed in absolute ethanol/glacial acetic acid $(3: 1, \mathrm{v} / \mathrm{v})$ for $24 \mathrm{~h}$ at room temperature and stored at $-20{ }^{\circ} \mathrm{C}$ until further analysis. Fixed root tips were washed in $10 \mathrm{mM}$ citrate buffer $\mathrm{pH} 4.6$ and digested in a solution of $4 \%$ cellulase, $1 \%$ pectolyase and $4 \%$ hemicellulase at $37{ }^{\circ} \mathrm{C}$ for about $30 \mathrm{~min}$. Digested root tips were macerated in a drop of $45 \%$ acetic acid and slides were coverslipped; coverslips were removed in liquid nitrogen and the slides were air dried. The best slides were stained in 2\% Giemsa and mounted in Entellan (Merck). Alternatively, some slides were prepared following the standard Feulgen method. All observations were performed using a Zeiss Axioplan Universal photomicroscope.

\section{Genome size estimations}

Total DNA content was assessed by flow cytometry according to Marie and Brown (1993) and Dolezel et al. (2003). Petunia hybrida Vilm. 'PxPC6' (2C = 2.85 pg; Marie and Brown, 1993), Solanum lycopersicum L. 'Montfavet $63-5$ ' $(2 \mathrm{C}=1.99 \mathrm{pg}$, Lepers-Andrzejewski et al., $2011)$ and Pisum sativum L. 'Long Express' $(2 \mathrm{C}=8.37 \mathrm{pg}$, Marie and Brown, 1993) were used as internal standards. To release the nuclei into suspension, the material was chopped in $1 \mathrm{~mL}$ of a nuclear-isolation buffer (Galbraith et al., 1983) supplemented with $10 \mathrm{mM}$ sodium metabisulphite and 1\% polyvinylpyrrolidone 10000 and RNase (2.5 U/mL; Amresco, USA). The DNA content of 


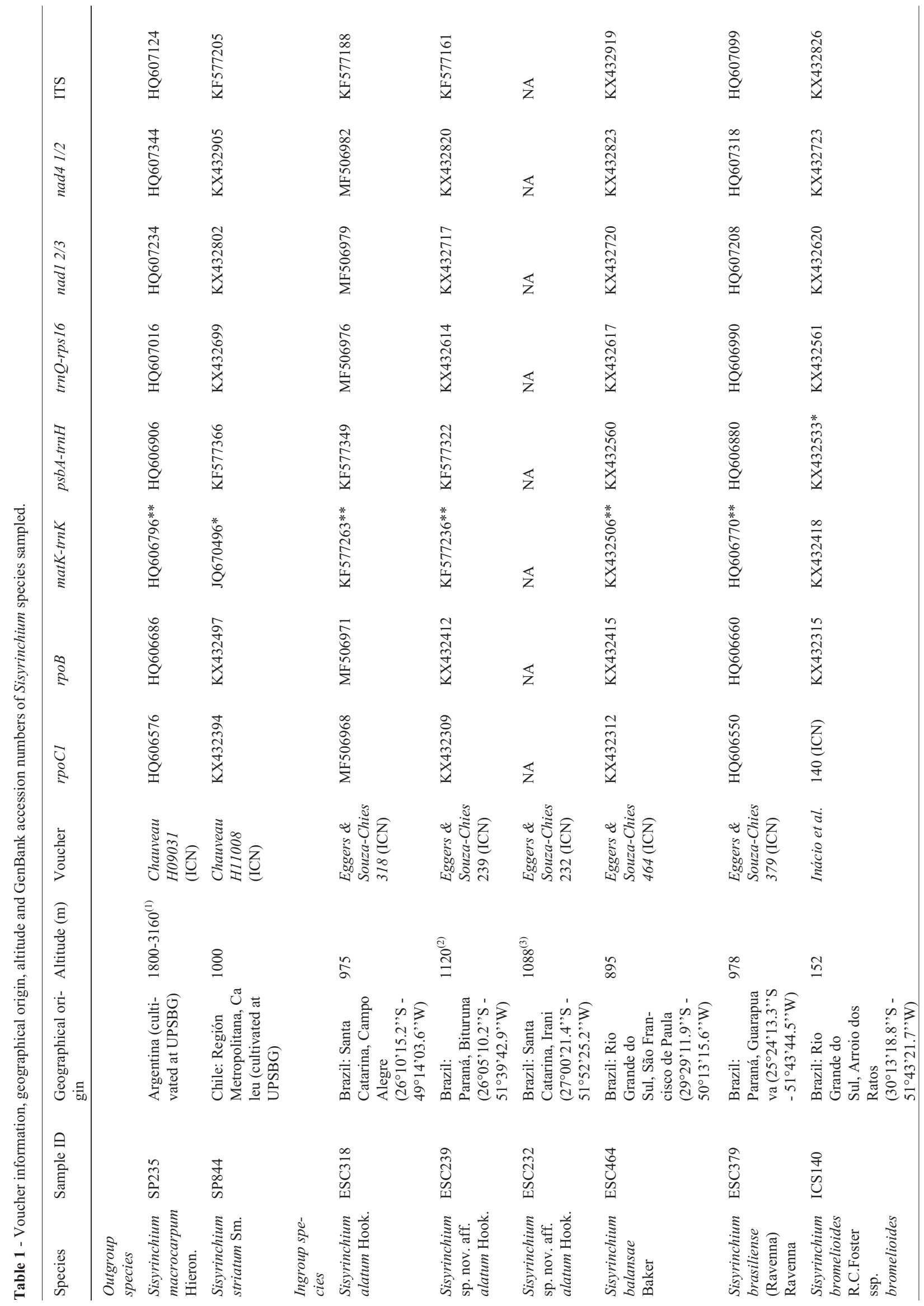




\begin{tabular}{|c|c|c|c|c|c|c|c|c|}
\hline$\hat{E}$ & $\begin{array}{l}0 \\
0 \\
0 \\
0 \\
0 \\
0 \\
0\end{array}$ & 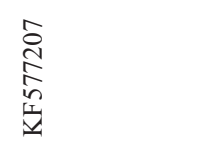 & 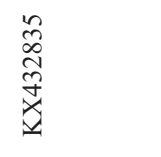 & 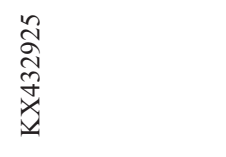 & $\overleftarrow{z}$ & $\frac{\mathbb{z}}{z}$ & $\overleftarrow{z}$ & 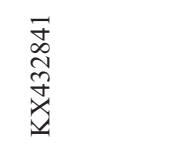 \\
\hline 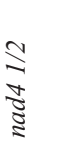 & 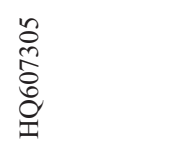 & 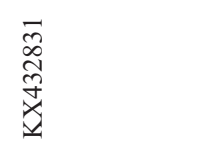 & 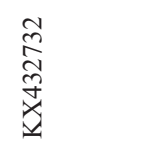 & 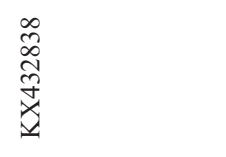 & 妾 & $\mathbb{z}$ & $\overleftrightarrow{z}$ & 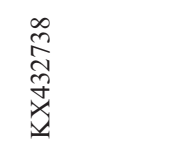 \\
\hline $\begin{array}{l}\text { In } \\
\text { ב̇ }\end{array}$ & $\begin{array}{l}\text { a } \\
\stackrel{2}{0} \\
\stackrel{0}{0} \\
\frac{1}{1}\end{array}$ & 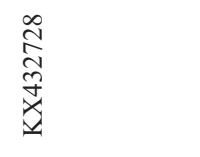 & 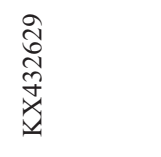 & 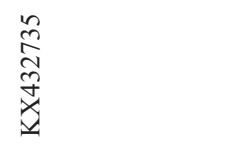 & $\mathbb{z}$ & $\overleftrightarrow{z}$ & $\overleftrightarrow{z}$ & 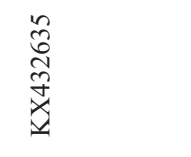 \\
\hline & 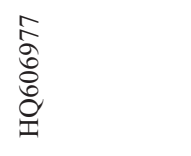 & 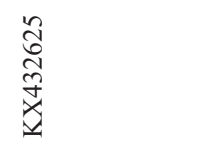 & 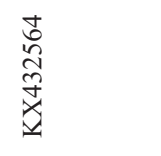 & 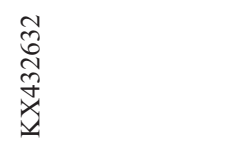 & $\overleftrightarrow{z}$ & $\overleftarrow{z}$ & $\overleftrightarrow{z}$ & 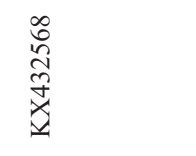 \\
\hline & $\begin{array}{l}\hat{0} \\
\text { o. } \\
0 \\
0 \\
0\end{array}$ & 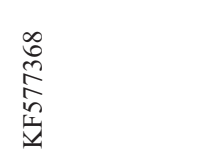 & 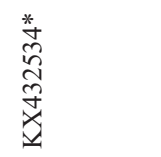 & 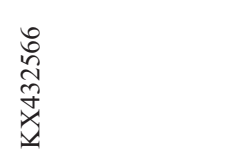 & $\overleftrightarrow{z}$ & $\frac{\pi}{z}$ & $\overleftarrow{z}$ & 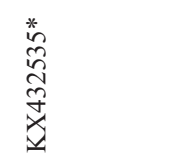 \\
\hline & 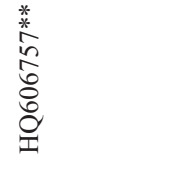 & 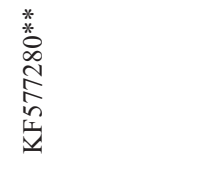 & 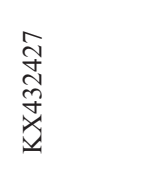 & 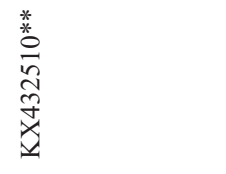 & $\overleftrightarrow{z}$ & $\mathbb{z}$ & $\overleftrightarrow{z}$ & 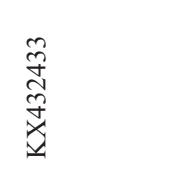 \\
\hline 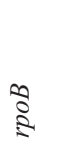 & 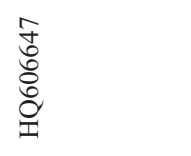 & 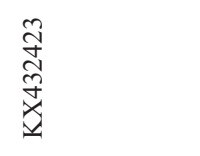 & 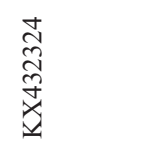 & 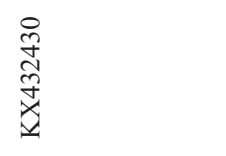 & $\overleftarrow{z}$ & $\overleftrightarrow{z}$ & $\overleftrightarrow{z}$ & 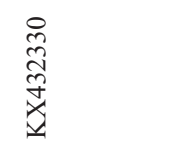 \\
\hline రั & 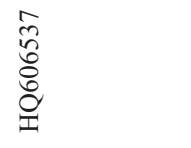 & 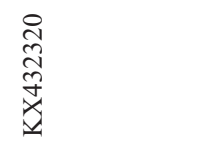 & 忌 & 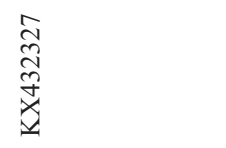 & $\overleftrightarrow{z}$ & $\overleftrightarrow{z}$ & $\overleftrightarrow{z}$ & 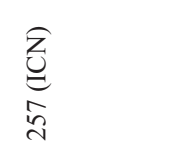 \\
\hline & 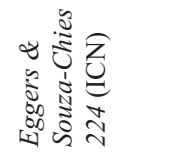 & 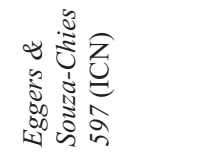 & 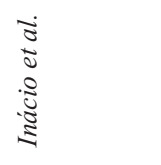 & 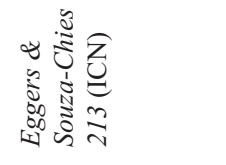 & 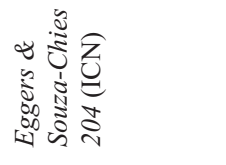 & 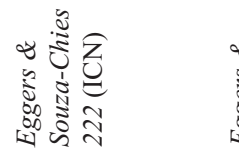 & 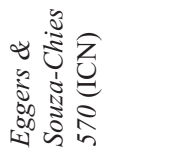 & 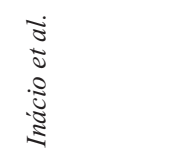 \\
\hline 焉 & $\begin{array}{l}\infty \\
\stackrel{\infty}{\Im}\end{array}$ & $\stackrel{\tilde{n}}{\underline{a}}$ & $\stackrel{\infty}{\varrho}$ & 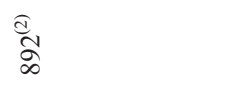 & f & $\stackrel{\sqrt[c]{m}}{\stackrel{m}{=}}$ & $\stackrel{\infty}{\stackrel{\circ}{\circ}}$ & $\stackrel{\infty}{\infty}$ \\
\hline 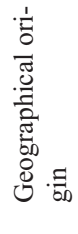 & 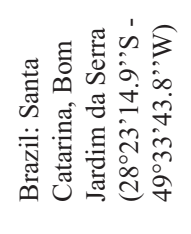 & 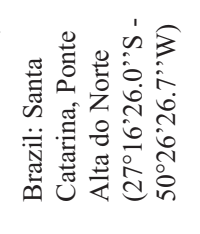 & 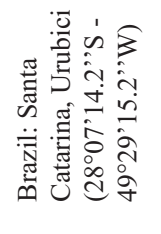 & 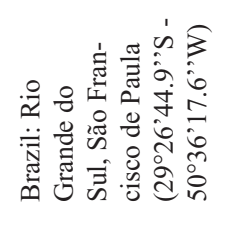 & 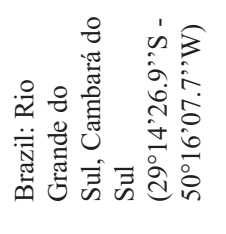 & 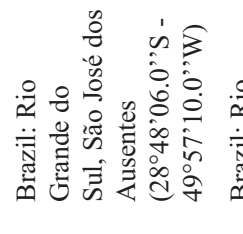 & 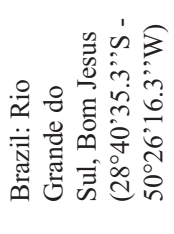 & 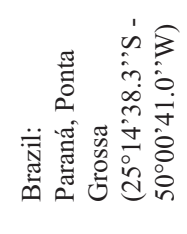 \\
\hline 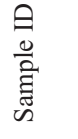 & $\begin{array}{l}\text { 芯 } \\
\text { 品 }\end{array}$ & 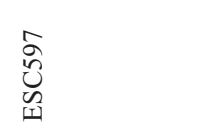 & 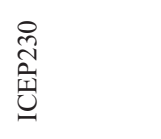 & 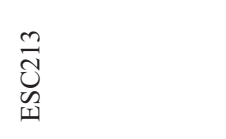 & $\begin{array}{l}\text { 志 } \\
\text { 㟧 }\end{array}$ & 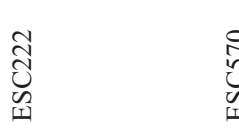 & 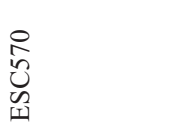 & 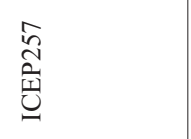 \\
\hline 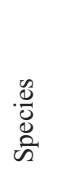 & 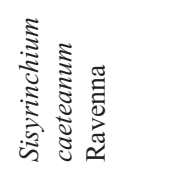 & 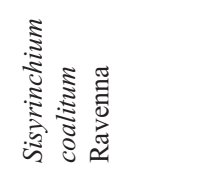 & 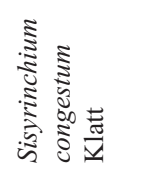 & 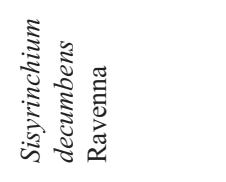 & 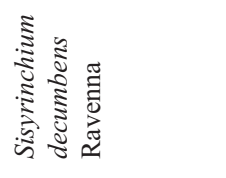 & 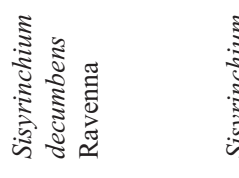 & 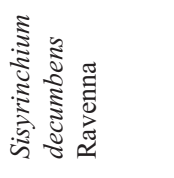 & 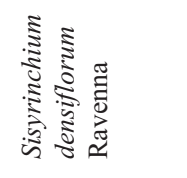 \\
\hline
\end{tabular}




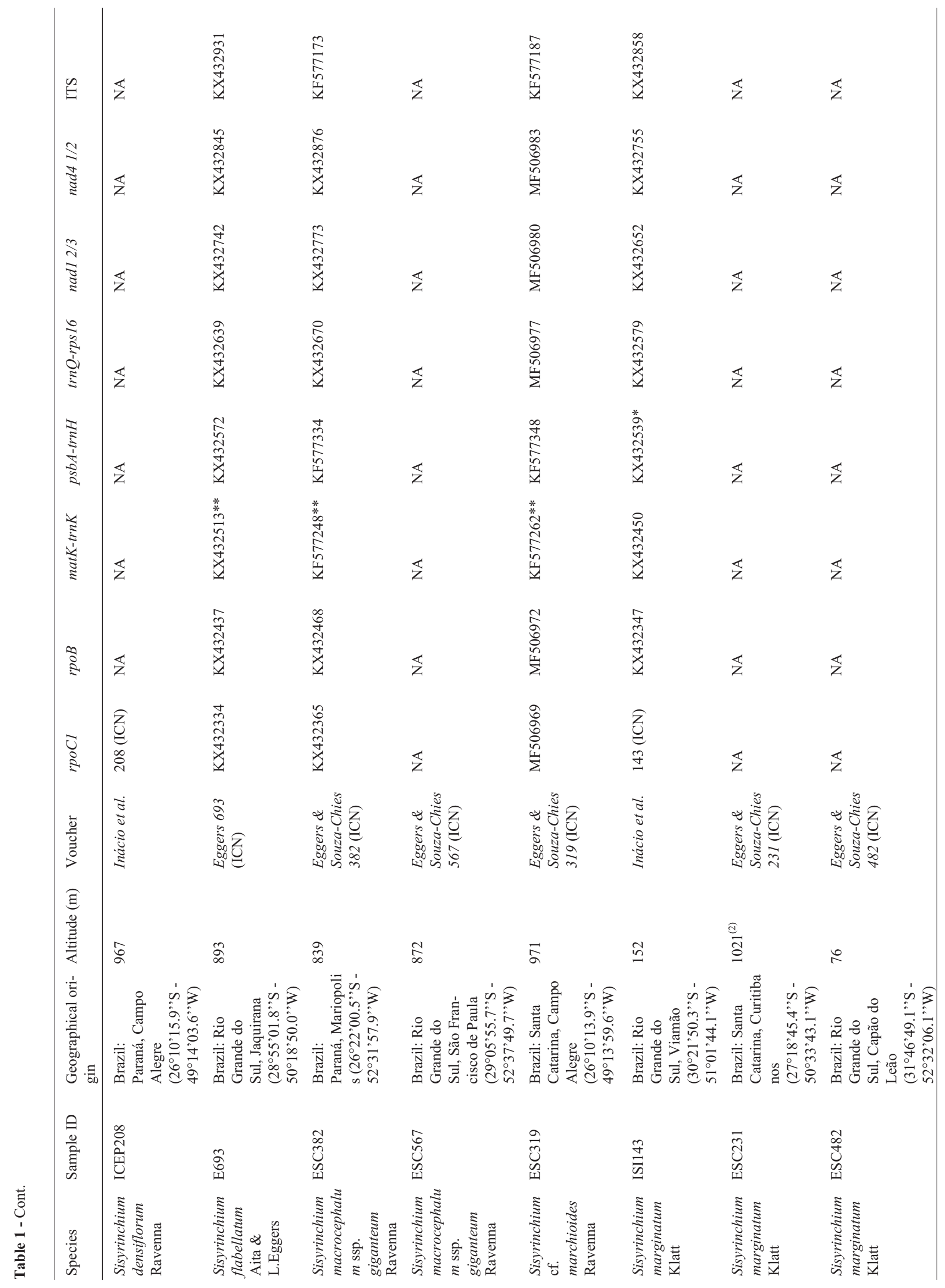




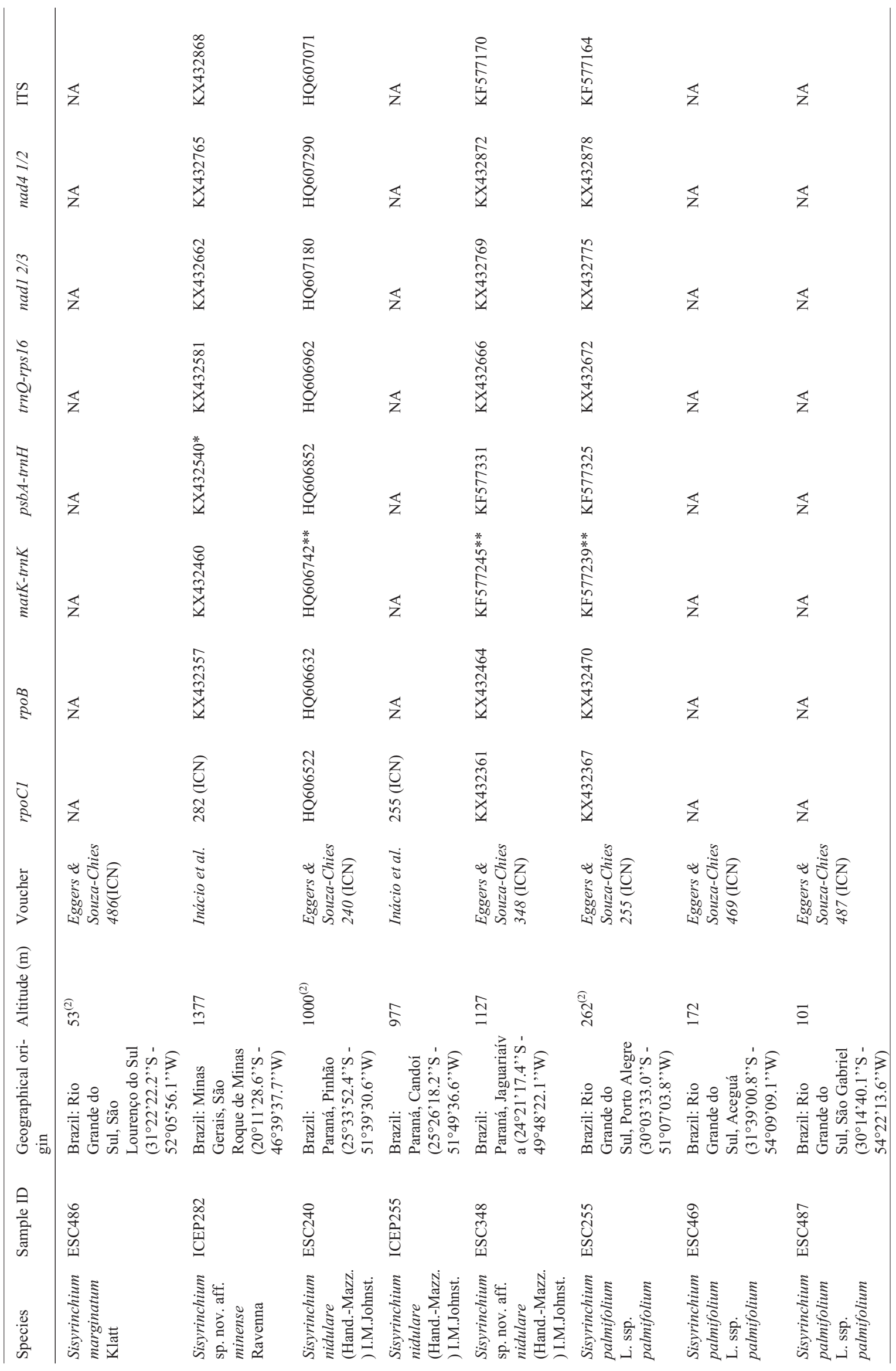




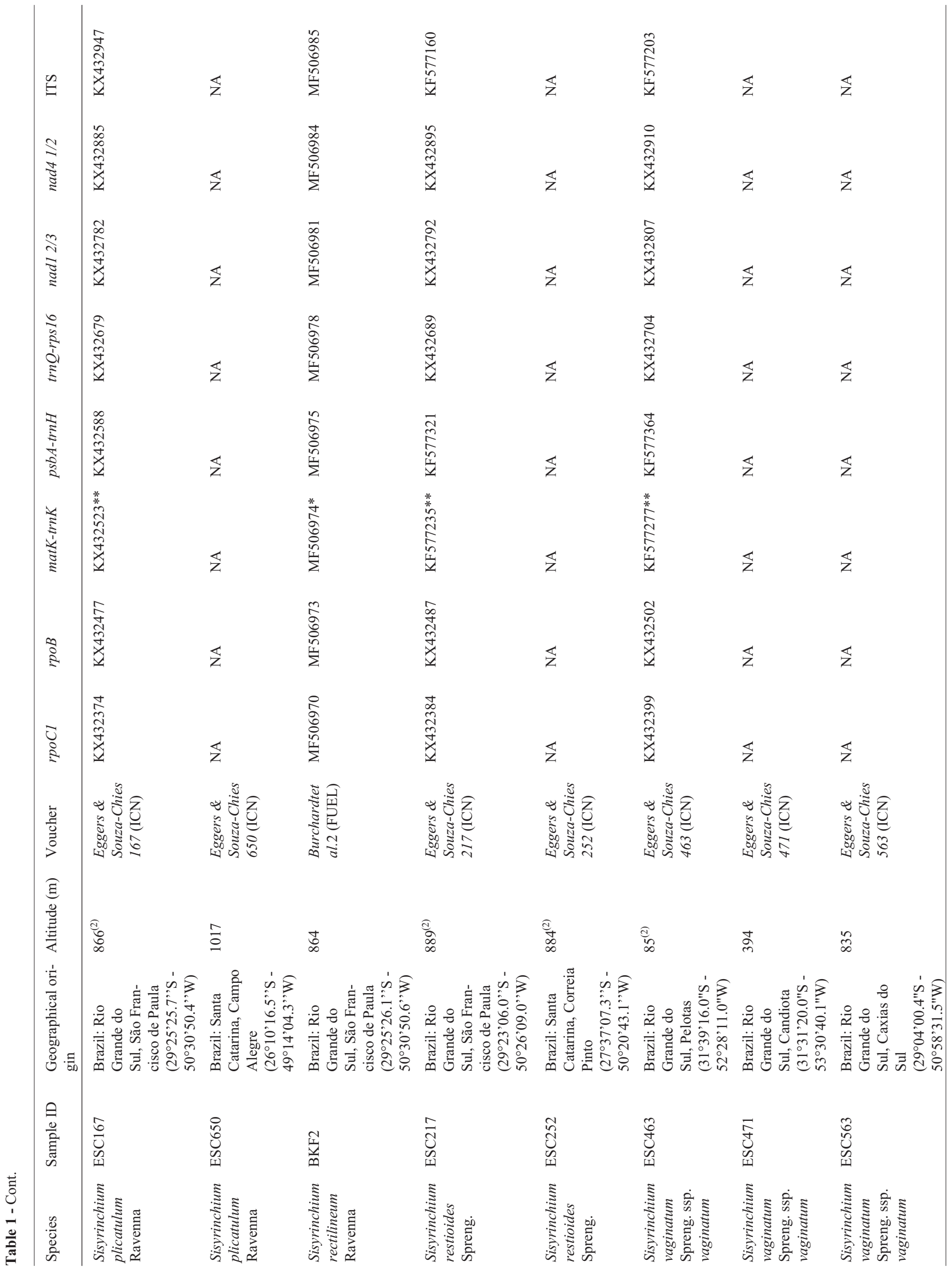




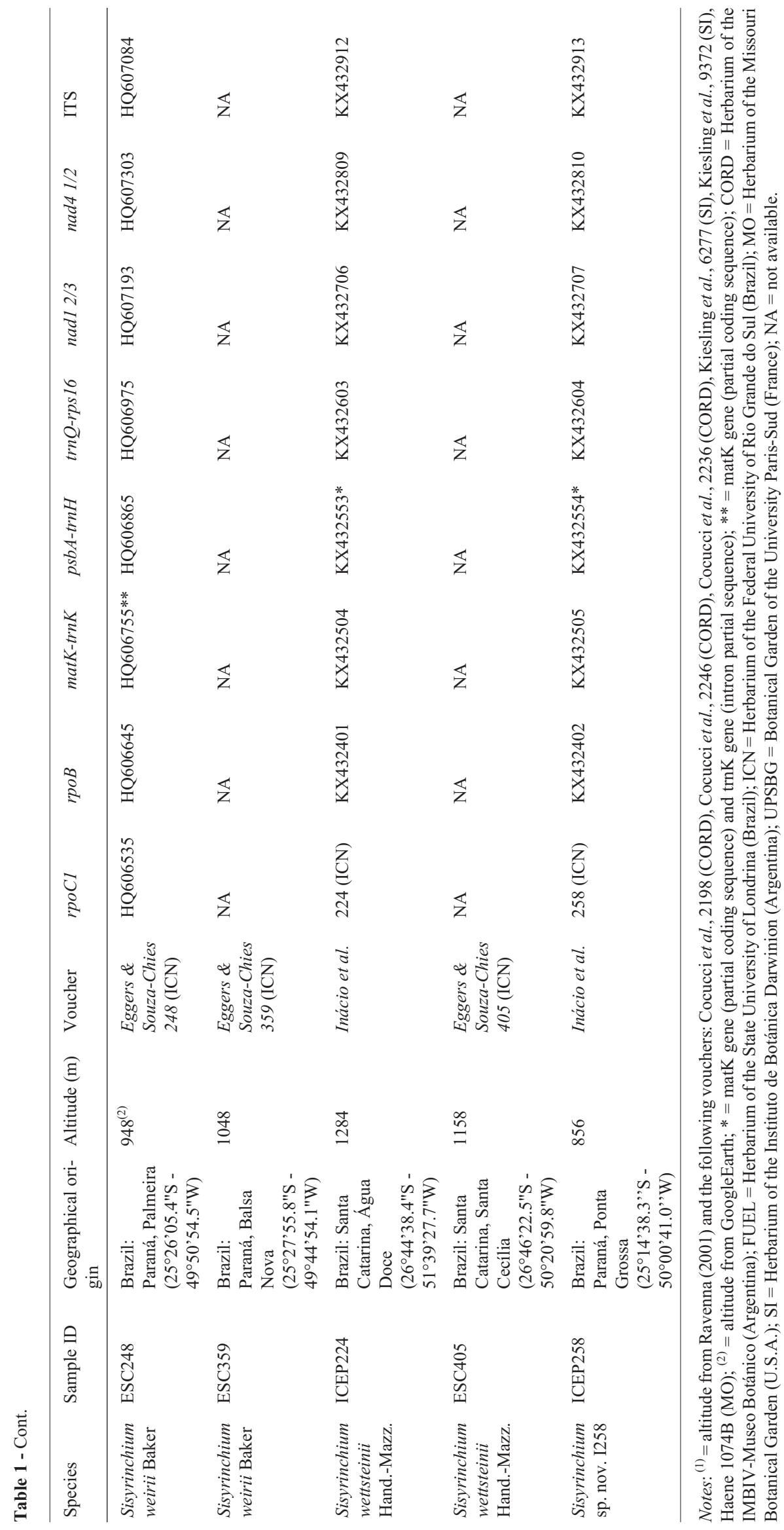


Table 2 - Accession numbers, sampling for phylogenetic analyses, chromosome numbers, ploidy levels, 2C DNA content (pg and Mbp) and monoploid genome sizes (1C $x$ value) of Sisyrinchium species included in the study.

\begin{tabular}{|c|c|c|c|c|c|c|}
\hline Species & Sample ID & DNA sequences & $2 n$ (ploidy level) & $2 \mathrm{C}(\mathrm{pg})$ & $2 \mathrm{C}(\mathrm{Mbp})$ & $1 \mathrm{C} x(\mathrm{pg})$ \\
\hline \multicolumn{7}{|l|}{ Outgroup species } \\
\hline S. macrocarpum & SP235 & $\mathrm{X}$ & $18(2 x)$ & 2.19 & 2142 & 1.09 \\
\hline S. striatum & SP844 & $\mathrm{X}$ & $18(2 x)$ & 2.71 & 2650 & 1.35 \\
\hline \multicolumn{7}{|l|}{ Ingroup species } \\
\hline S. alatum & ESC318 & $\mathrm{X}$ & $36(4 x)$ & 7.30 & 7139 & 1.83 \\
\hline S. subsp. nov. aff. alatum & ESC239 & $\mathrm{X}$ & $18(2 x)$ & 4.03 & 3941 & 2.01 \\
\hline S. subsp. nov. aff. alatum & ESC232 & NA & $18(2 x)$ & NA & NA & NA \\
\hline S. balansae & ESC464 & $\mathrm{X}$ & $18(2 x)$ & 2.55 & 2494 & 1.28 \\
\hline S. brasiliense & ESC379 & $\mathrm{X}$ & NA & 4.68 & 4577 & NA \\
\hline S. bromelioides ssp. bromelioides & ISC140 & $\mathrm{X}$ & NA & NA & NA & NA \\
\hline S. caeteanum & ESC224 & $\mathrm{X}$ & NA & 8.17 & 7990 & NA \\
\hline S. coalitum & ESC597 & $\mathrm{X}$ & NA & NA & NA & NA \\
\hline S. congestum & ICEP230 & $\mathrm{X}$ & NA & NA & NA & NA \\
\hline S. decumbens & ESC213 & $\mathrm{X}$ & $18(2 x)$ & 2.08 & 2034 & 1.04 \\
\hline S. decumbens & ESC204 & NA & $18(2 x)$ & 2.71 & 2650 & 1.35 \\
\hline S. decumbens & ESC222 & NA & $18(2 x)$ & 2.65 & 2592 & 1.32 \\
\hline S. decumbens & ESC570 & NA & $18(2 x)$ & 2.64 & 2582 & 1.32 \\
\hline S. densiflorum & ICEP257 & $\mathrm{X}$ & NA & NA & NA & NA \\
\hline S. densiflorum & ICEP208 & NA & $18(2 x)$ & 3.84 & 3755 & 1.92 \\
\hline S. flabellatum & E693 & $\mathrm{X}$ & $18(2 x)$ & 2.99 & 2924 & 1.49 \\
\hline S. macrocephalum subsp. giganteum & ESC382 & $\mathrm{X}$ & $18(2 x)$ & 4.80 & 4694 & 2.40 \\
\hline S. macrocephalum subsp. giganteum & ESC567 & NA & $18(2 x)$ & 4.76 & 4655 & 2.38 \\
\hline S. cf. marchioides & ESC319 & $\mathrm{X}$ & $36(4 x)$ & 5.69 & 5565 & 1.42 \\
\hline S. marginatum & ISI143 & $\mathrm{X}$ & $18(2 x)$ & 4.90 & 4792 & 2.45 \\
\hline S. marginatum & ESC231 & NA & $18(2 x)$ & NA & NA & NA \\
\hline S. marginatum & ESC482 & NA & $18(2 x)$ & NA & NA & NA \\
\hline S. marginatum & ESC486 & NA & $18(2 x)$ & NA & NA & NA \\
\hline S. sp. nov. aff. minense & ICEP282 & $\mathrm{X}$ & NA & NA & NA & NA \\
\hline S. nidulare & ICEP255 & NA & $18(2 x)$ & 3.75 & 3667 & 1.87 \\
\hline S. nidulare & $\mathrm{ESC} 240$ & $\mathrm{X}$ & $18(2 x)$ & 3.34 & 3266 & 1.67 \\
\hline S. sp. nov. aff. nidulare & ESC348 & $\mathrm{X}$ & NA & NA & NA & NA \\
\hline S. palmifolium subsp. palmifolium & ESC255 & $\mathrm{X}$ & $18(2 x)$ & 4.74 & 4636 & 2.37 \\
\hline S. palmifolium subsp. palmifolium & ESC469 & NA & $18(2 x)$ & NA & NA & NA \\
\hline S. palmifolium subsp. palmifolium & ESC487 & NA & $18(2 x)$ & 4.75 & 4645 & 2.38 \\
\hline S. plicatulum & ESC167 & $\mathrm{X}$ & $18(2 x)$ & 4.85 & 4743 & 2.42 \\
\hline S. plicatulum & ESC650 & NA & $18(2 x)$ & NA & NA & NA \\
\hline S. rectilineum & BKF 2 & $\mathrm{X}$ & $18(2 x)$ & 5.30 & 5183 & 2.65 \\
\hline S. restioides & $\mathrm{ESC} 217$ & $\mathrm{X}$ & $18(2 x)$ & NA & NA & NA \\
\hline S. restioides & $\mathrm{ESC} 252$ & NA & $18(2 x)$ & NA & NA & NA \\
\hline S. vaginatum subsp. vaginatum & ESC463 & $\mathrm{X}$ & $18(2 x)$ & 2.68 & 2621 & 1.34 \\
\hline S. vaginatum subsp. vaginatum & ESC471 & NA & $18(2 x)$ & 2.60 & 2542 & 1.30 \\
\hline S. vaginatum subsp. vaginatum & ESC563 & NA & $18(2 x)$ & 2.29 & 2240 & 1.14 \\
\hline S. weirii & ESC248 & $\mathrm{X}$ & $54(6 x)$ & 7.77 & 7599 & 1.29 \\
\hline S. weirii & ESC359 & NA & $54(6 x)$ & 6.96 & 6807 & 1.16 \\
\hline S. wettsteinii & ICEP224 & $\mathrm{X}$ & $18(2 x)$ & 4.35 & 4254 & 2.17 \\
\hline S. wettsteinii & ESC405 & NA & $18(2 x)$ & NA & NA & NA \\
\hline S. sp. nov. I258 & ICEP258 & $\mathrm{X}$ & NA & NA & NA & NA \\
\hline
\end{tabular}

Notes: NA $=$ not available. 
Table 3 - Viability, dimensions and morphology of pollen grains from Sisyrinchium species.

\begin{tabular}{|c|c|c|c|c|c|c|c|}
\hline \multirow[t]{2}{*}{ Species } & \multicolumn{2}{|c|}{ Viability } & \multirow[t]{2}{*}{$\mathrm{N}^{*}$} & \multirow{2}{*}{$\begin{array}{c}\text { Polar axis }(\mathrm{P}) \\
(\mu \mathrm{m})\end{array}$} & \multirow{2}{*}{$\begin{array}{l}\text { Equatorial diameter } \\
\qquad(\mathrm{E})(\mu \mathrm{m})\end{array}$} & \multirow{2}{*}{$\begin{array}{l}\text { Ratio } \\
(\mathrm{P} / \mathrm{E}) \\
\text { Mean }\end{array}$} & \multirow[t]{2}{*}{ Morphology } \\
\hline & $\mathrm{N}^{*}$ & $\%{ }^{\#}$ & & & & & \\
\hline S. alatum & $1(500)$ & 98.50 & $1(20)$ & 36.00 & 43.10 & 0.84 & suboblate \\
\hline S. balansae & $1(500)$ & 99.30 & $1(20)$ & 24.80 & 31.10 & 0.80 & suboblate \\
\hline S. decumbens & $9(4500)$ & 96.33 & $7(140)$ & 28.09 & 31.26 & 0.90 & oblate spheroidal \\
\hline S. macrocephalum subsp. giganteum & $5(2500)$ & 99.08 & $5(100)$ & 26.12 & 31.41 & 0.83 & suboblate \\
\hline S. marginatum & $20(10000)$ & 93.01 & $20(400)$ & 31.42 & 35.58 & 0.88 & oblate spheroidal \\
\hline S. nidulare & $4(2000)$ & 87.70 & $4(80)$ & 31.90 & 33.75 & 0.95 & oblate spheroidal \\
\hline S. palmifolium subsp. palmifolium & $5(2500)$ & 97.28 & $5(100)$ & 28.58 & 32.32 & 0.89 & oblate spheroidal \\
\hline S. rectilineum & $5(2500)$ & 97.68 & $5(100)$ & 28.56 & 31.53 & 0.91 & oblate spheroidal \\
\hline S. restioides & $1(500)$ & 97.80 & $1(20)$ & 34.60 & 35.70 & 0.97 & oblate spheroidal \\
\hline S. sp. nov. aff. alatum & $1(500)$ & 22.70 & $1(20)$ & 44.90 & 43.30 & 1.04 & prolate spheroidal \\
\hline S. weirii & $1(500)$ & 93.50 & $1(20)$ & 35.90 & 41.60 & 0.86 & suboblate \\
\hline S. wettsteinii & $5(2500)$ & 93.72 & $5(100)$ & 29.48 & 32.59 & 0.90 & oblate spheroidal \\
\hline
\end{tabular}

Notes: ${ }^{*} \mathrm{~N}$, number of individuals analyzed (number of cells). "Percentage of normal cells.

5,000-10,000 stained nuclei was determined for each sample using either an Elite ESP (Beckman-Coulter, Brea, CA, USA), a Partec CyFlow or a FACSAria II (Becton Dickinson, Franklin Lakes, NJ, USA) flow cytometer. For each measurement of DNA content, 3-5 samples were assessed and the average value was used as the $2 \mathrm{C}$ content for the following analyses. The total $2 \mathrm{C}$ DNA value was calculated as: sample peak mean / standard peak mean $\times 2 \mathrm{C}$ DNA content of standard (pg). The term 'monoploid genome size' $(1 \mathrm{C} x)$ was used to represent the DNA content of one nonreplicated genome with basic chromosome number $x$ (Greilhuber et al., 2005), whereas 2C refers to the whole GS of a somatic cell.

\section{Meiotic analysis}

Flower buds were fixed in ethanol/glacial acetic acid $(3: 1, \mathrm{v} / \mathrm{v})$ for $24 \mathrm{~h}$ at room temperature and kept at $-20^{\circ} \mathrm{C}$. For slide preparation, anthers were washed in distilled water and squashed in $1 \%$ propionic carmine. Slides were examined and documented with an Axioplan Universal photomicroscope (Zeiss, Oberkochen, Germany). All available phases of meiosis I and II were analyzed. Abnormalities, such as non-orientated bivalents and multivalents in metaphase I, bridges and laggards in anaphase and telophases I and II, were evaluated. Meiotic indexes were calculated from 200 pollen tetrads per plant using the formula: $\mathrm{MI}=$ (number of normal tetrads/total number of tetrads) $\times 100$. Microcytes and micronuclei, bridges, and unequally sized cells were considered abnormalities. Chromosome numbers were determined in diakinesis (prophase I).

\section{Pollen stainability and morphology}

Pollen stainability and pollen morphology were used to assess pollen viability. Flowers buds at preanthesis were collected, fixed and stored as described above. Slides were prepared following Alexander's method (Alexander, 1980), in which empty, non-viable pollen grains stain green, whereas full, viable pollen grains stain purple. Samples of 500 pollen grains per flower were analyzed from at least one individual per taxon. In order to determine pollen grain shape, measurements of the polar axis $(\mathrm{P})$ and equatorial diameter (E) of 20 mature pollen grains per individual were performed after Alexander's staining method. The $\mathrm{P} / \mathrm{E}$ ratios of the grains were used to classify pollen morphology according to Erdtman (1971).

\section{Statistical analysis}

The DNA content $2 \mathrm{C}$ and $1 \mathrm{C} x$ were compared between diploids and polyploids using Student's $t$-test, whereas one-way ANOVA followed by Tukeys multiple comparisons tests were employed to compare taxa for these variables. Data of one population, at random, was used when data of more than one population was available for a determined taxon. The ploidy level of two taxa (S. brasiliense and $S$. caeteanum) of unknown chromosome number was inferred taking into account their $2 \mathrm{C}$ content, using two approaches: a cluster analysis using squared Euclidian distance and centroid linkage in order to group taxa, and a discriminant analysis, using prior membership probabilities based on the number of known diploid and polyploid species (13 and 3 species, respectively). A p-value of 0.05 was considered the threshold for statistical significance. 
Sequence data, alignments and phylogenetic analyses

Newly sequenced specimens were field-collected and genomic DNA was extracted from 10-15 mg silica-dried leaf material using a modified CTAB protocol with volumes adjusted to $2 \mathrm{~mL}$ tubes (Doyle and Doyle, 1990). A combination of nine coding and non-coding DNA plastid, mitochondrial and nuclear regions previously used by Chauveau et al. (2011, 2012) was selected (i.e. matK, rpoCl, rpoB, matK-5'trnK, psbA-trnH, trnQ-rps 16, nad1$2 / 3$, nad4-1/2 and ITS). DNA primers and PCR amplification protocols were the same as those described in Chauveau et al. $(2011,2012)$. All PCR products were sent to the Molecular Biology and Genetic Engineering Centre of the State University of Campinas (CBMEG/UNICAMP, SP, Brazil) for sequencing. CodonCode Aligner 6.0.2 (CodonCode Corp., Dedham, MA, USA) was used to edit chromatograms and contigs. Nineteen new DNA sequences were generated for this study and sequences already deposited in GenBank were added to complete our data set. Alignments of DNA sequences were conducted with MAFFT 7 (Katoh and Standley, 2013) and manually validated with MEGA6 (Tamura et al., 2013). Unambiguously aligned gaps shared by two or more taxa were coded with SeqState 1.4.1 (Müller, 2005), according to the Modified Complex Indel Coding approach (Simmons et al., 2007).

Phylogenetic analyses were conducted using two parametric methods: Maximum Likelihood (ML) with bootstrapping in RAxML 8.2.9 (Stamatakis, 2014) and Bayesian inference (BI) with MrBayes 3.2.6 (Ronquist et al., 2012). ML and BI analyses were initially performed on each DNA region separately, and then on cpDNA and mtDNA markers respectively combined, to detect potential outliers or incongruence among loci or genomes. Conflicts were explored through visual examination of resulting ML trees and comparison of nodes with $\geq 70 \%$ bootstrap support. These separate analyses were all conducted with RAxML as implemented on the XSEDE server of the CIPRES Science Gateway (Miller et al., 2010) following a three-step process: (1) a thorough ML search with 200 randomized starting trees to find the best-scored likelihood tree; (2) non-parametric bootstrap statistics (-b) calculated from 1,000 thorough bootstrap iterations; and (3) bootstrap values were mapped on the best-scored tree. A GTRGAMMA model was used in each step with data partitioned for each gene, intron or spacer region, and codon position in the regions coding for proteins to accommodate locus-specific variations. Gap-coded characters were also partitioned by locus. All data were then combined for subsequent analyses. The Maximum Likelihood analysis of the total evidence data set was performed following the threestep process previously described, whereas partitioned MrBayes analysis was conducted with two independent runs of four chains each and eight million generations, sampling trees every 1,000 generations, using the models se- lected with the Akaike information criterion (AIC) by MrModeltest 2.3 (Nylander, 2004) for each partition (Table S2). Gap-coded characters were included as additional datatype and treated using a simple model with variable rates. Convergence was verified by checking the average deviation of split frequencies $(<0.01)$, the Effective Sample Size $($ ESS $>200)$ and the Potential Scale Reduction Factor (0.99 $<$ PSRF < 1.01) reported by MrBayes. Default value was used for the burn-in phase and a majority-rule consensus tree was computed. Phylogenetic trees resulting from ML and BI analyses (ML best-scoring tree and BI majority-rule tree) were rooted on $S$. macrocarpum $+S$. striatum and combined to manually build a highly conservative consensus tree that summarizes the results of both analyses at once. A given node was kept in the consensus tree only if the ML bootstrap support was $\geq 70 \%$ or if the PP was $\geq 0.95$ and in the absence of topological conflict among ML and BI trees.

\section{Ancestral character state reconstructions and regression analyses}

The consensus topology (Figure 1) was used for discrete character optimization (i.e., chromosome number) with the maximum parsimony (MP) and ML methods implemented in MESQUITE 3.10 (Maddison and Maddison, 2016). With MP, character states were treated as unordered, allowing any transition among states. ML optimization was conducted using the MK1 model of evolution (Schluter et al., 1997; Pagel, 1999), which gives equal probability for changes between all character states. For continuous character optimizations (i.e., DNA content (2C) and altitude) a pruned phylogram was generated by reducing the phylogeny obtained in the current study to terminals for which we had genome size data. Maximum likelihood ancestral state reconstructions were performed using the contMap command of phytools package (Revell, 2012) in R 3.4.1 (R Core Team, 2017).

We used a multiple regression-type approach to test for adaptive adjustment of the genome size to elevation. The altitude data were log transformed and the pruned phylogram was used for phylogenetic generalized least squares (PGLS) regressions. A non-phylogenetic linear least squares regression analysis was performed in $\mathrm{R}$ and, to account for dependence of species values due to phylogenetic relatedness, PGLS regressions were conducted with the packages nlme (Pinheiro et al., 2017) and caper (Orme et $a l ., 2013)$ in R. Analyses were performed with different alternative evolutionary models: Pagel's $\lambda$ (Pagel, 1997) with constraint and unconstraint values, Ornstein-Uhlenbeck (Hansen, 1997) and a Brownian motion model (Felsenstein, 1985). 


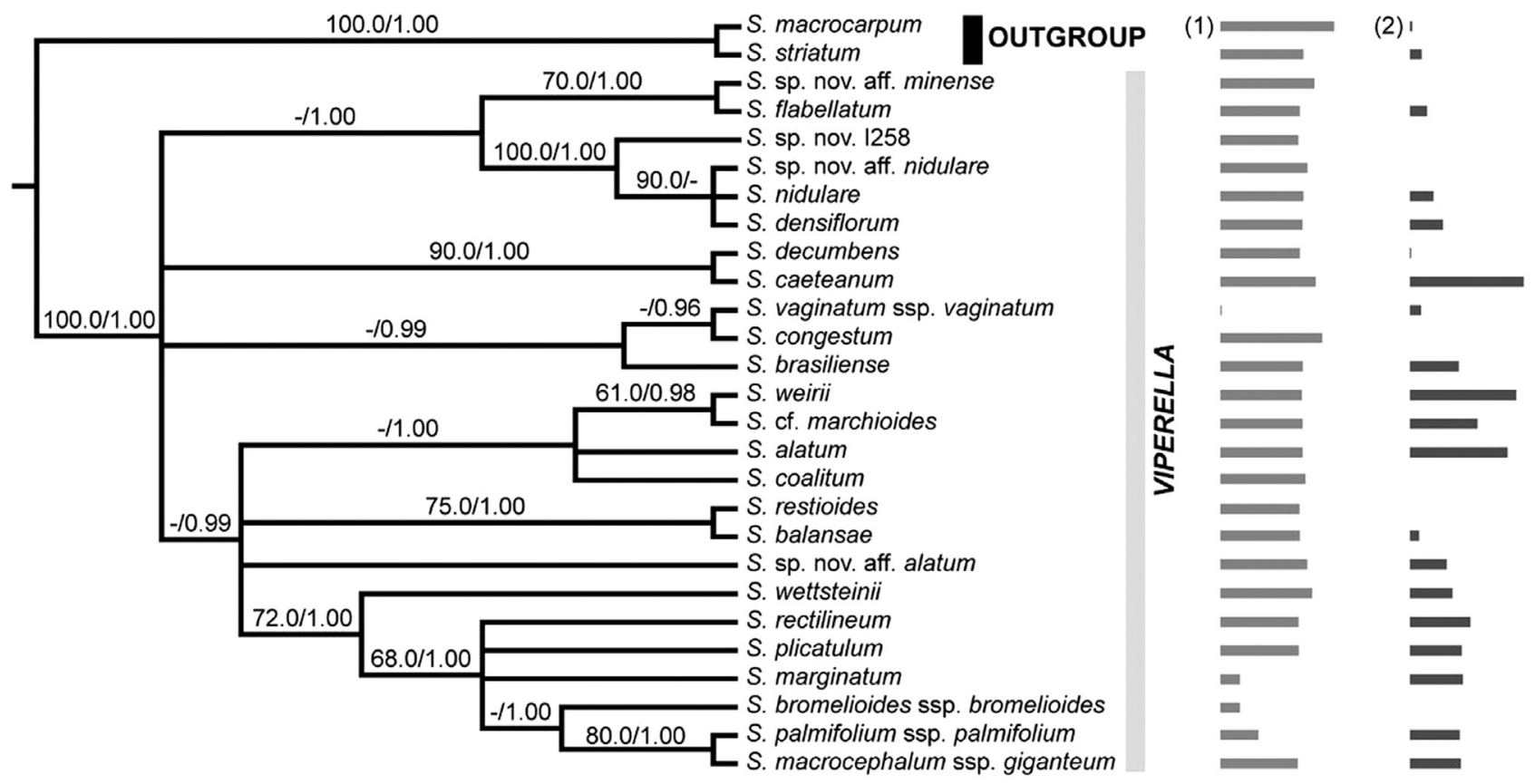

Figure 1 - Strict consensus tree based on the estimated maximum likelihood tree and the Bayesian $50 \%$ majority rule consensus tree obtained from the analyses of the whole molecular data set. The tree is rooted using Sisyrinchium striatum + S. macrocarpum as outgroup. Support values indicated above branches follow the order likelihood bootstrap support (LBS)/ Bayesian posterior probability (PP) and are provided for a given node only if one of the values reached the following thresholds: LBS $\geq 70 \%$ or PP $\geq 0.95$. A dash (-) indicates support value of less than $50 \%$ for LBS or less than 0.95 for PP. For each taxon, (1) horizontal light grey bars indicate normalized natural log values of altitude, whereas (2) horizontal dark grey bars show normalized DNA content $(2 \mathrm{C})$ values.

\section{Results}

\section{Chromosome numbers, karyotypes and genome size}

Chromosome counts for 17 taxa are presented here in Table 2 (excluding outgroup species); all but one (S. alatum) had their number determined for the first time. Most taxa are diploids $(2 n=2 x=18)$, and only three of them are polyploids (Sisyrinchium alatum and $S$. cf. marchioides are $2 n=4 x=36$ and $S$. weirii is $2 n=6 x=54$ ). Despite this ploidy variation, all taxa had the same base chromosome number $x=9$. Intraspecific polyploidy or cytotype variation were not found for any species.

Although chromosome measurements were not carried out in any species, a remarkable difference in the size of chromosomes could be observed among the analyzed taxa. The smallest chromosomes were those of $S$. decumbens and S. wettsteinii (Figure 2A and $\mathrm{H}$, respectively), and the largest chromosomes were found in $S$. macrocephalum subsp. giganteum (Figure 2E). With regard to chromosome size, Sisyrinchium decumbens and S. densiflorum (Figure $2 \mathrm{~A}$ and $\mathrm{B}$, respectively) apparently have more symmetrical karyotypes, while, S. macrocephalum subsp. giganteum and $S$. palmifolium subsp. palmifolium seemed to have the most asymmetrical karyotypes, comprising large and small chromosome pairs. The first one has at least three pairs of satellited chromosomes and the second species with one satellite pair was clearly observed (Figure 2E and F respectively).

Concerning DNA amount, we observed $2 \mathrm{C}$ ranging from $2 \mathrm{C}=2.08 \mathrm{pg}$ in $S$. decumbens to $2 \mathrm{C}=8.17 \mathrm{pg}$ in $S$. caeteanum (Table 2, Figure $3 \mathrm{~A}$ ), representing a difference of more than 3-fold in genome size. As expected, the $2 \mathrm{C}$ values increased according to ploidy level $(t=4.67, p<$ $0.001, \mathrm{n}=13$ diploid and 3 polyploid species), with smaller DNA content in diploids (mean \pm SD: $3.92 \pm 0.99 ; \mathrm{n}=13$ species) and higher in the polyploids (tetraploids $S$. cf. marchioides $2 \mathrm{C}=5.69$ and $S$. alatum $2 \mathrm{C}=7.30 \mathrm{pg}$; hexaploid S. weirii $2 \mathrm{C}=7.77 \mathrm{pg}$; mean \pm SD: $6.92 \pm 1.09 ; \mathrm{n}=3$ species). Although $S$. caeteanum presented the largest genome ( $8.17 \mathrm{pg})$, compared to the other species, its chromosome number and ploidy could not be ascertained. On the other hand, taking into account only the 13 diploid taxa (all $2 n=18$ ), the DNA content varied greatly, ranging from $2 \mathrm{C}$ $=2.08$ to $5.30 \mathrm{pg}$, evidencing an increase in $2 \mathrm{C}$ DNA content not associated with the ploidy level (Figure 3A). Monoploid genome sizes $(1 \mathrm{C} x)$ ranged from $1.04 \mathrm{pg}$ to $2.65 \mathrm{pg}$ (Table 2, Figure 3B). Tetraploids had $1 \mathrm{C} x$ values in average lower than most diploid taxa (mean \pm SD: $1.62 \pm 0.29 ; n=2$ species), and the hexaploid showed one of the smallest $1 \mathrm{C} x$ $(1.16 \mathrm{pg})$ (see Figure 3B). However, the average difference in $\mathrm{C} x$ between diploids and polyploids was not statistically significant $(t=1.49, p=0.159)$.

Chromosome number could not be determined for Sisyrinchium brasiliense and S. caeteanum, therefore the 


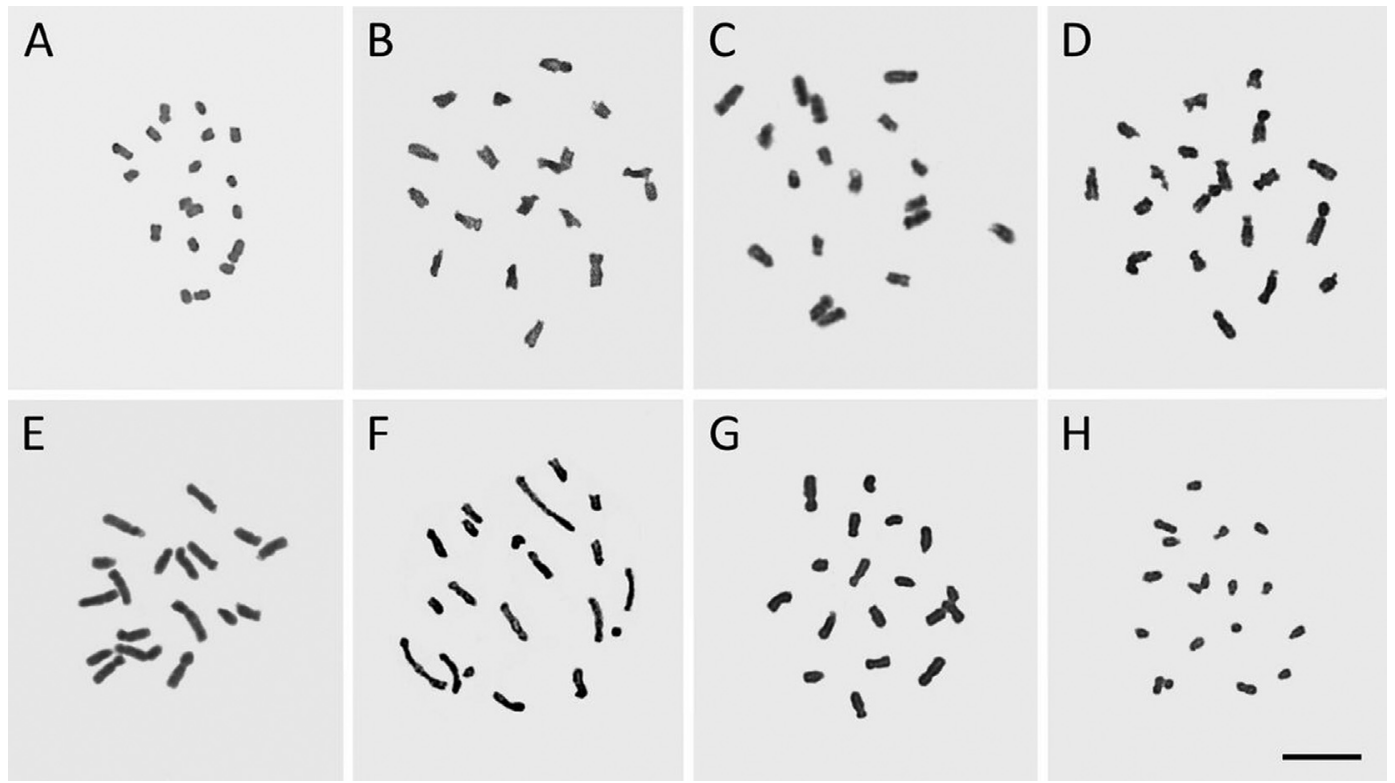

Figure 2 - Mitotic metaphases/prometaphase of Sisyrinchium taxa. A, S. decumbens; B, S. densiflorum; C, S. flabellatum; D, S. marginatum; E, S. macrocephalum subsp. giganteum; F, S. palmifolium subsp. palmifolium; G, S. rectilineum; H, S. wettsteinii. Note that all have the same $2 n=18$, but present remarkably different karyotypes in regards to chromosome size and shape (p.e. A $\times$ E). Satellites are only recognizable in $\mathrm{E}$ and $\mathrm{F}$. Bar in $\mathrm{H}$ represents $10 \mu \mathrm{m}$.

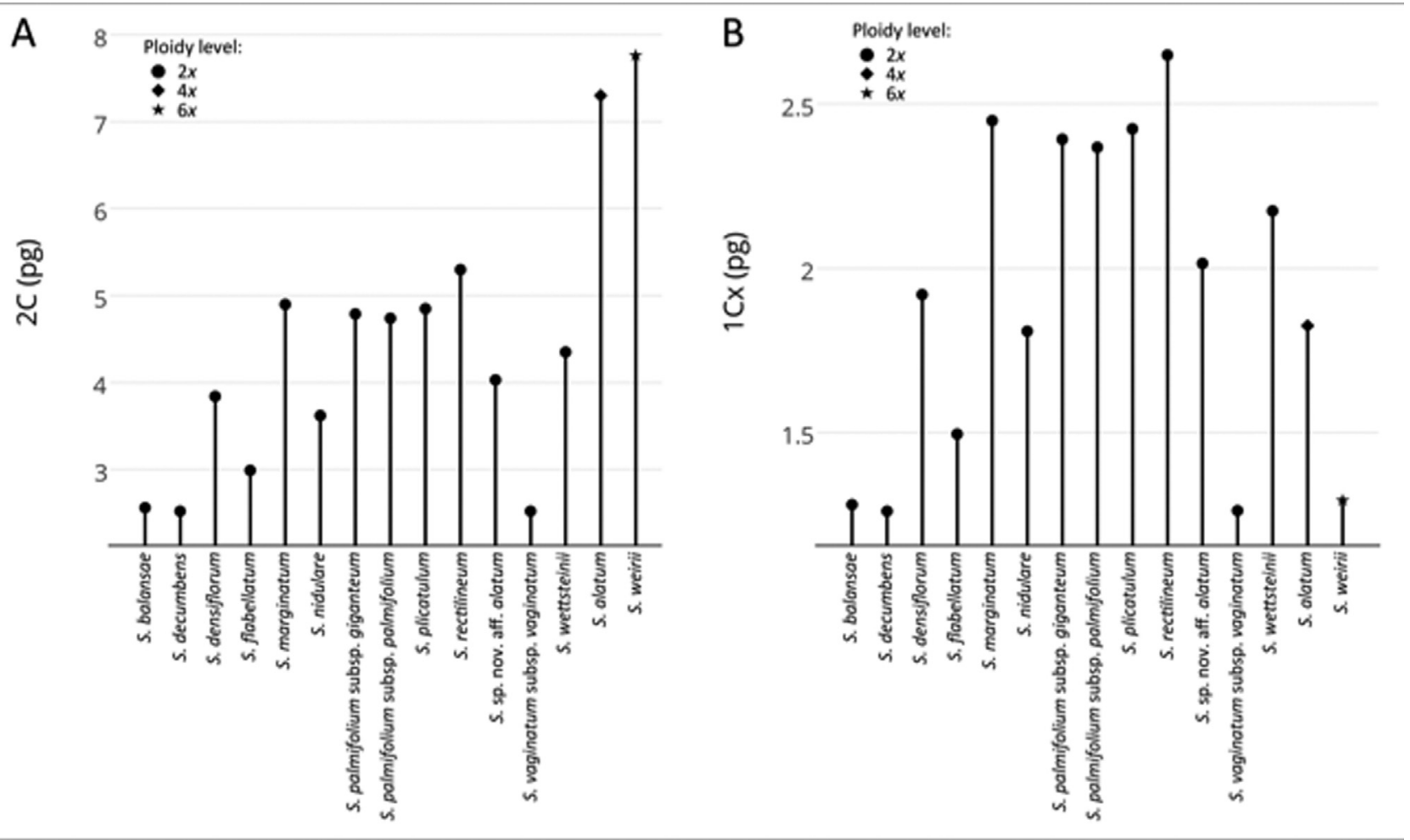

Figure 3 - Distribution of DNA content (2C) (A) and monoploid genome size (1Cx) (B) among Sisyrinchium taxa. Ploidy levels are indicated as circle $(2 x), \operatorname{star}(4 x)$ or hexagon $(6 x)$.

$1 \mathrm{C} x$ value could not be calculated either. Aiming to infer the ploidy level of these taxa, we performed a discriminant analysis and constructed a dendrogram based on the $2 \mathrm{C}$ content of all taxa. The discriminant function was statisti- cally significant $(p<0.001)$, and all but one taxa of known ploidy were correctly classified. The exception was the tetraploid $S$. cf. marchioides, which was classified as diploid due to its intermediate $2 \mathrm{C}$ value $(5.69 \mathrm{pg})$. This taxon 
grouped with diploids in the cluster analysis also (Figure S1). Based on the discriminant analysis, the diploid group membership probabilities for the two species of undetermined ploidy were 0.975 for $S$. brasiliense and 0.001 for $S$. caeteanum. Therefore, even though we were unable to determine chromosome numbers of S. brasiliense and S. caeteanum, the statistical analysis of genome sizes indicates that they probably are diploid and polyploid (possibly tetraor hexaploid), respectively.

\section{Meiotic behavior and pollen viability/morphology}

All taxa presented highly regular meiosis (97.11-99.45\%; Table S1; Figure 4). The most common abnormalities were non-oriented bivalents, metaphases with stickiness (Figure 4I) and anaphase bridges (Figure $4 \mathrm{~J}$ ) in either anaphase I or anaphase II, sometimes with fragments or laggards. Multivalents and univalents were not observed in any taxa. The meiotic indexes were high for all taxa (> 95\%; Table S1) and they had at least $87 \%$ viable pollen grains (Table 3), except for Sisyrinchium sp. nov. aff. alatum which had a very low pollen viability $(22.70 \%)$. Pollen grains were classified into three distinct morphologies according to their $\mathrm{P} / \mathrm{E}$ ratio (Table 3). We found that most taxa have oblate spheroidal pollens, while only one species (Sisyrinchium sp. nov. aff. alatum) has prolate spheroidal pollen grains. The smallest pollen measures were observed in $S$. balansae and the largest were those from $S$. sp. nov. aff. alatum, both diploid species.

\section{Phylogenetic analyses}

Since no significantly supported incongruence was detected among tree topologies obtained from independent analyses of each DNA marker (data not shown), all DNA regions from the three genomic compartments were concatenated for subsequent analyses. The combined alignment reached 8565 characters divided into 8535 nucleotide positions and 30 coded indels. Plastid, mitochondrial and nuclear regions contained, respectively, 4639, 3272 and 684 characters. The number of potentially informative sites was $123(2.65 \%)$ for the cpDNA data set, $70(2.14 \%)$ for the mtDNA matrix and $54(7.89 \%)$ for the ITS alignment. ML and Bayesian analyses of the total combined data set produced similar topologies. Therefore, the ML best-scored tree and the $50 \%$ majority-rule BI tree were summarized as a strict consensus phylogeny presented in Figure 1, with nodes supported above $70 \%$ by ML bootstrap estimates or 0.95 by BI posterior probability values.

\section{Ancestral character state reconstructions and regression analyses}

The MP and ML analyses of the diploid chromosome number $(2 n)$ evolution on the strict consensus tree produced consistent results (Figure 5), and both phylogenetic uncertainty and missing data had little effect on reconstructed ancestral states at key nodes. Character optimiza- tions suggested that the common ancestor of sect. Viperella was probably diploid $(2 n=2 x=18)$, with two subsequent polyplodization events within the section. One transition towards tetraploidy occurred at the base of the clade formed by $S$. coalitum, $S$. alatum, $S$. cf. marchioides and $S$. weirii, and the hexaploid condition of the latter species was probably derived from the common tetraploid ancestor of $S$. cf. marchioides $+S$. weirii.

Total DNA content (2C) varied considerably and repeatedly across the phylogeny (Figure 6, Tree 1), with conspicuously larger genomes in polyploid species and in $S$. caeteanum. ML optimization of genome size evolution suggested that the section's ancestral state was intermediate $(2 \mathrm{C}$ of ca. $4.72 \mathrm{pg}$ ) and was relatively higher at the base of $S$. alatum $+S$. cf. marchioides $+S$. weirii $(2 \mathrm{C}$ of ca. $6.05 \mathrm{pg}$ ) and the clade formed by $S$. caeteanum and $S$. decumbens ( $2 \mathrm{C}$ of ca. $6.65 \mathrm{pg}$ ). Altitude also varied repeatedly across the phylogeny (Figure 6, Tree 2), and the ML optimization of this environmental factor along the phylogeny showed that the ancestor of Viperella probably occurred at ca. $790 \mathrm{~m}$ elevation. However, the ancestral state analysis did not reveal a specific pattern of evolution in relation to genome size.

Significant phylogenetic signals were not detected for both genome size (2C) and altitude when measured using Pagel's $\lambda$ and Blomberg's $K$ (Table 4). Moreover, results of non-phylogenetic linear least squares regression and phylogenetic generalized least squares (PGLS) regressions (Table 5) showed that no significant relationship $(p>0.05)$ was found between the magnitude or direction of DNA content changes and natural log of altitude in our data set.

\section{Discussion}

\section{Karyotype and GS evolution}

The data obtained here demonstrate that base chromosome number $x=9$ is constant among taxa of sect. Viperella which is also the most frequent in Southern Hemisphere Sisyrinchium species (Kenton and Heywood, 1984). Thus, this is a constant character within the clade, in which the absence of dysploidy and few polyploidy events were observed. Diploid chromosome number $(2 n=18)$ was estimated as the ancestral condition of the section and polyploidy is a derived character restricted to only three species (Figure 5), suggesting that this phenomenon was not important to the evolution of this group, contrary to almost all other Iridoideae from South America (Moraes et al., 2015). Notwithstanding the role of polyploidy in Iridaceae evolution, diploids and lower polyploids (tetra- and hexaploids) are most frequent among Southern Hemisphere Sisyrinchium (Tacuatiá et al., 2012, 2016). The optimization of ploidy level shown in Figure 5 evidenced that a polyploidization event gave rise to the tetraploid $S$. alatum and S. cf. marchioides and the hexaploid S. weirii; while, the hexaploid condition was probably derived from the 

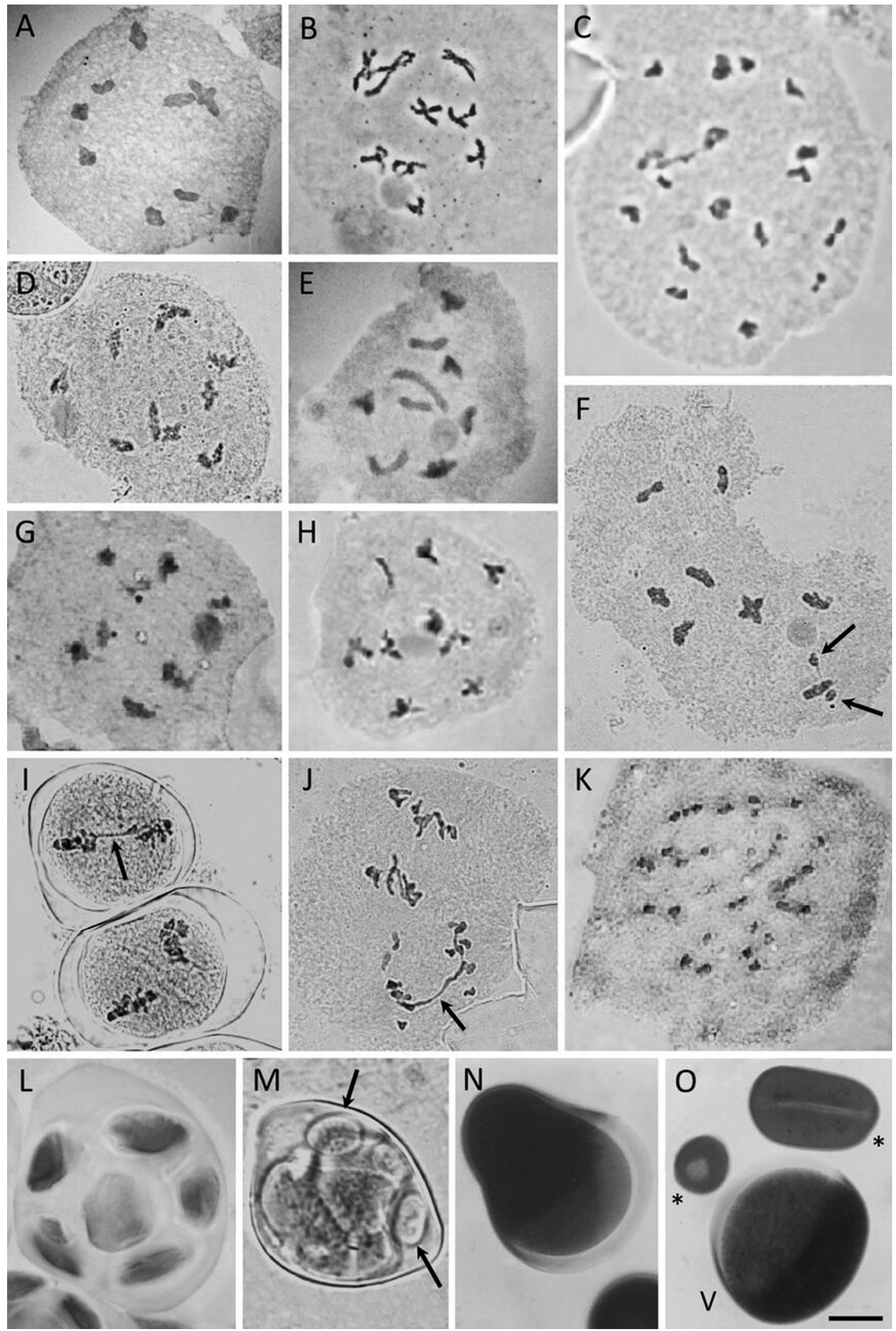

Figure 4 - Meiotic analysis of Sisyrinchium taxa - haploid chromosome numbers and observed meiotic abnormalities. A, S. palmifolium subsp. palmifolium, $n=9$ (prophase I - diakinesis); B, S. marginatum, $n=9$ (prophase I - diplotene); C, S. alatum, $n=18$ (prophase I - diakinesis); D, S. decumbens, $n=9$ (prophase I - diakinesis); E, S. macrocephalum subsp. giganteum, $n=9$ (prophase I - diakinesis); F, S. rectilineum, $n=9$, in diakinesis with two univalents (arrows); G, S. sp. nov. aff. alatum, $n=9$ (prophase I - diakinesis); H, S. restioides, $n=9$ (prophase I - diakinesis); I, S. rectilineum in metaphase I with stickiness (arrow); J, S. rectilineum in anaphase II with bridge (arrow); K, S. weirii, $n=27$ (prophase I - diakinesis); L, S. palmifolium subsp. palmifolium showing 'tetrad' with several microspores; M, S. rectilineum showing tetrad with microcytes (arrows); N, S. marginatum showing an abnormally shaped pollen grain; O, S. marginatum showing viable pollen grain (V) and two unviable pollen grains $(*)$. Bar in $\mathrm{O}$ represents $10 \mu \mathrm{m}$. 
Table 4 - Tests for phylogenetic signal of DNA content (2C) and altitude (natural log; m) among taxa of Sisyrinchium used in the present study.

\begin{tabular}{lcccc}
\hline & $K$ & $P$-value & $\lambda$ & $P$-value \\
\hline Genome size & 0.487 & 0.449 & 0.457 & 0.415 \\
log of altitude & 0.134 & 0.533 & $6.6 * 10^{-5}$ & 0.691 \\
\hline
\end{tabular}

Notes: Blomberg's K and Pagel's $\lambda$ were calculated using the phylosig command in phytools (Revell, 2012) in R.

Table 5 - Tests for adaptive adjustments of the DNA content (2C)-altitude (natural log; $\mathrm{m}$ ) relationship among taxa of Sisyrinchium used in the present study: results from the non-phylogenetic linear least squares regression and phylogenetic generalized least squares (PGLS) regressions.

\begin{tabular}{lcccc}
\hline & AIC & Slope & Std. error & P-value \\
\hline$\underline{\text { Linear regression }}$ & NA & 0.504 & 1.247 & 0.690 \\
$\underline{\text { PGLS }}$ & & & & \\
Brownian motion & 81.632 & 0.504 & 0.651 & 0.449 \\
Ornstein-Uhlenbeck & 81.385 & 0.544 & 0.741 & 0.472 \\
Pagel's $\lambda$ : & & & & \\
$\lambda=0$ & 82.428 & 0.504 & 1.247 & 0.690 \\
$\lambda=1$ & 77.465 & 0.504 & 0.651 & 0.449 \\
$\lambda$ unconstraint & 81.418 & 0.964 & 1.111 & 0.397 \\
\hline
\end{tabular}

common tetraploid ancestor of $S$. cf. marchioides $+S$. weirii, as was already proposed here.

Polyploid cytotypes have been reported in some Iridaceae species, such as $S$. micranthum ( $4 x$ and $6 x$; Tacuatiá et al., 2012), S. sellowianum Klatt (4x; Fachinetto et al., 2018) and Herbertia lahue (Molina) Goldblatt (4x, $6 x$ and 8x; Moraes et al., 2015; Stiehl-Alves et al., 2016). However, in this study we did not find any cytotypes within taxa. Different populations/localities (see Tables 1 and 2) were sampled for $S$. decumbens, $S$. marginatum, $S$. vaginatum subsp. vaginatum and S. palmifolium subsp. palmifolium, but different chromosome numbers were not found in any accessions for these taxa. Hence, events of intraspecific polyploidization apparently did not take place within taxa of sect. Viperella.

A noticeable chromosome size variation was observed among the studied Viperella taxa, as previously reported for other South American species of Sisyrinchium (Kenton and Heywood, 1984; Rudall et al., 1986). Even without chromosome measurements performed for such species, it is possible to see that Sisyrinchium decumbens presents the most symmetrical karyotype and has also the smallest DNA content, while S. palmifolium subsp. palmifolium has a more asymmetrical karyotype and a considerably higher DNA amount. This pattern has been reported across Liliaceae (Peruzzi et al., 2009), indicating that increases in genome size were generally accompanied by increasing karyotype asymmetry. In future studies, it might be interesting to test the association between the symmetry and the homogeneity of certain environmental variables, such as climatic or geographic parameters.

In relation to the character genome size, an intermediate $2 \mathrm{C}$ value was the ancestral state from which genome size increases and decreases took place, as is remarkable for S. decumbens. Probably, all these transitions could be interpreted as independent or homoplasious events and thus, the increment of genome size does not necessarily correspond to speciation events in this clade. Considering the occurrence of only three polyploid species in this section, it seems that the transitions towards larger genome size are not related to polyploidy.

Although Iridaceae presents a large range of $2 \mathrm{C}$ values from 0.96 to $62.76 \mathrm{pg}$ (Bennett and Leitch, 2012), Sisyrinchium is known to display much smaller values, that vary between $2 \mathrm{C}=1.00$ and $2 \mathrm{C}=8.40 \mathrm{pg}$ and a monoploid genome size $(1 \mathrm{C} x)$ ranging from 0.32 to $3.56 \mathrm{pg}$ (Kenton et al., 1986). Estimates of DNA amounts for Sisyrinchium species are reported solely for 30 taxa, less than $22 \%$ of the total number of species in the genus (Kenton et al., 1986). All taxa examined in the present work, except $S$. alatum, had their genome size estimated for the first time. According to the size categories established by Leitch et al. (2005), most of the investigated Sisyrinchium representatives (12 species; $60 \%$ ) fall within the category of small genome sizes $(2.8 \leq 2 \mathrm{C}<7 \mathrm{pg})$; five species $(25 \%)$ have very small $(2 \mathrm{C}<2.8)$ and only three present intermediate $(7 \leq 2 \mathrm{C}<28)$ genome sizes. In our study, taxa of sect. Viperella, although with variable genome sizes, present the same base chromosome number $(x=9)$, as seen in sect. Echthronema (sensu Benth. \& Hook.) (Kenton et al., 1986). Despite such relationships and similarities, the analyzed taxa differed greatly in their genome sizes, especially considering the three polyploid species.

Taxa studied herein presented intermediate to high $1 \mathrm{C} x$ values, with the smallest genomes in $S$. decumbens $(1 \mathrm{C} x=1.08 \mathrm{pg})$ and the largest in $S$. rectilineum $(1 \mathrm{C} x=2.65$ pg), both diploids. Considering that all diploid taxa have the same chromosome number $(2 n=18)$, it is noteworthy that the genome size of $S$. decumbens is approximately half of that found in $S$. rectilineum. Compared to diploids, the polyploids $S$. alatum, $S$. cf. marchioides and $S$. weirii presented a reduction in $1 \mathrm{C} x$, which is even higher in the hexaploid S. weirii. Such reduction could be a 'genome downsizing' effect, as widely reported for many polyploid species (Leitch and Bennett, 2004; Suda et al., 2007; Pellicer et al., 2010), including Sisyrinchium (Kenton et al., 1986; Tacuatiá et al., 2016). Although the difference in 1Cx content between diploids and polyploids was not statistically significant, our data suggest that genome downsizing may also be present in the section Viperella, but was not detected statistically, probably due to the small number of polyploid taxa. It has been reported that ploidy level, chromosome size and genome size increase with latitude and/or altitude for several Sisyrinchium species (Rudall et al., 
Tree 1

Parsimony reconstruction (character unordered)

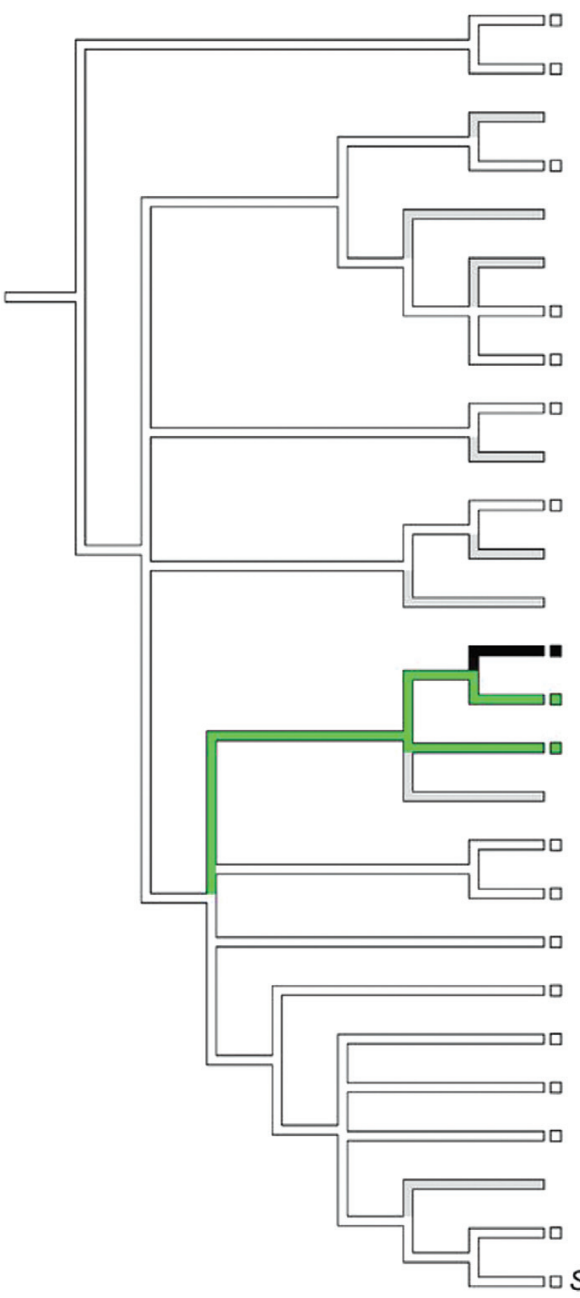

Chromosome number: $2 n$ (ploidy level)

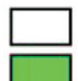
$18(2 x)$
$54(6 x)$
$36(4 x)$
Missing data

S. macrocarpum SP235

S. striatum SP844

S. sp. nov. aff. minense ICEP282

S. flabellatum $\mathrm{E} 693$

S. sp. nov. 1258

S. sp. nov. aff. nidulare ESC348

S. nidulare ESC240

S. densiflorum ICEP257

S. decumbens ESC213

S. caetanum $\mathrm{ESC} 224$

S. vaginatum ssp. vaginatum ESC463

S. congestum ICEP230

S. brasiliense ESC379

S. weirii $\mathrm{ESC} 248$

S. cf. marchioides ESC319

S. alatum ESC318

S. coalitum ESC597

S. restioides $\mathrm{ESC} 217$

S. balansae ESC464

S. sp. nov. aff. alatum ESC239

S. wettsteinii ICEP224

S. rectilineum BKF2

S. plicatulum ESC167

S. marginatum ISI143

S. bromelioides ssp. bromelioides ISC140 S. palmifolium ssp. palmifolium ESC255 S. macrocephalum ssp. giganteum ESC382

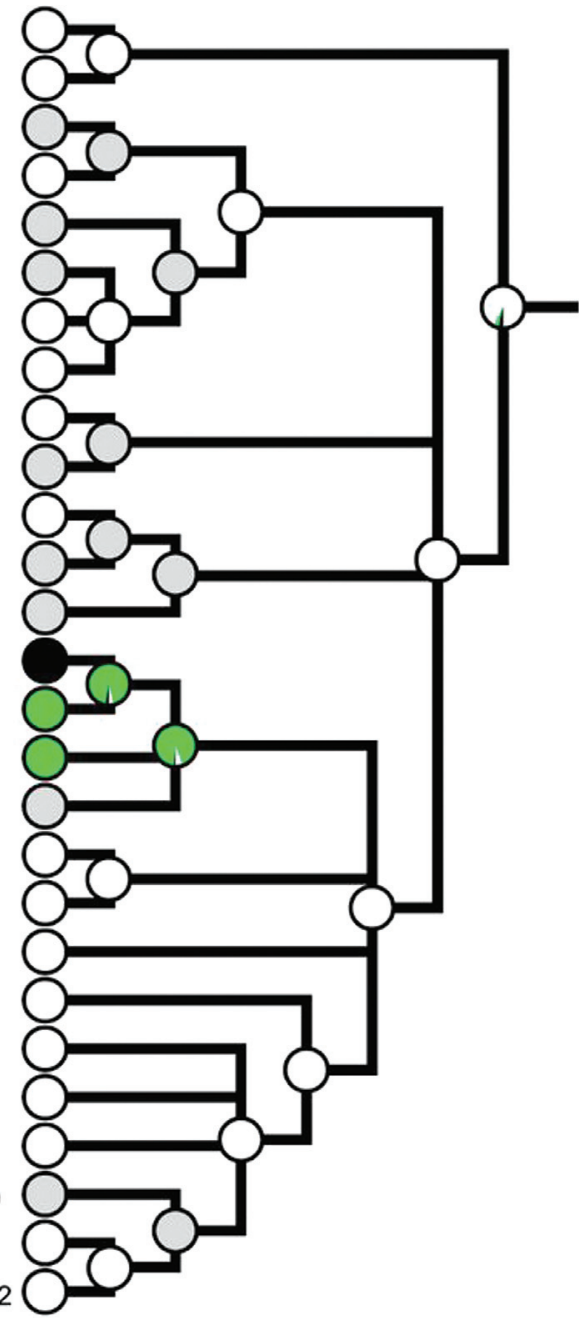

Tree 2

Likelihood reconstruction (model MK1)

Figure 5 - Mirror trees showing MP (Tree 1) and ML (Tree 2) optimizations of diploid chromosome numbers ( $2 n$ ) on the strict consensus tree. External nodes are coloured according to the character state observed, whereas internal nodes are coloured according to the ancestral state inferred (Tree 1) or to the relative likelihood values calculated for each character state (Tree 2). Missing data are indicated in grey.

1986; Kenton et al., 1986). In our study, variability in genome size could not be attributed to altitude, once significant phylogenetic signals were not detected in the regression analysis (see Table 5 and Figure 6), in spite of the occurrence of all polyploid species in altitudes higher than $900 \mathrm{~m}$ (Table 1).

Different proportions of repetitive DNA sequences, especially transposable elements (TE), can also cause genome size variation in plants (Bennetzen et al., 2005; Leitch and Leitch, 2012). Thus, differential TE activity might be a mechanism behind $2 \mathrm{C}$ content variation found in diploids from our data set. Slow growing, long lived species might contain greater accumulation of repetitive sequences than faster developing species (Charlesworth et al., 1994), providing an explanation for the larger genomes of the perennial taxa studied here compared to the annual species investigated by Tacuatiá et al. (2016). Thus, future work aiming repetitive DNA sequences characterization in this group of species should be done.

\section{Meiotic behavior and pollen viability}

The meiotic behavior and pollen viability data obtained here are relevant to the investigation of the mechanisms of polyploidy involved in the evolutionary process. As expected, almost all diploid taxa presented a regular meiosis and high pollen viability. Although meiotic behavior and meiotic indexes were not analyzed for polyploid species, elevated pollen viability was found in $S$. alatum $(98.50 \%, 2 \mathrm{n}=4 \mathrm{x}=36)$ and $S$. weirii $(93.5 \%, 2 \mathrm{n}=6 \mathrm{x}=54)$, indicating meiotic regularity and male-fertile plants. Such 
Tree 1: genome size

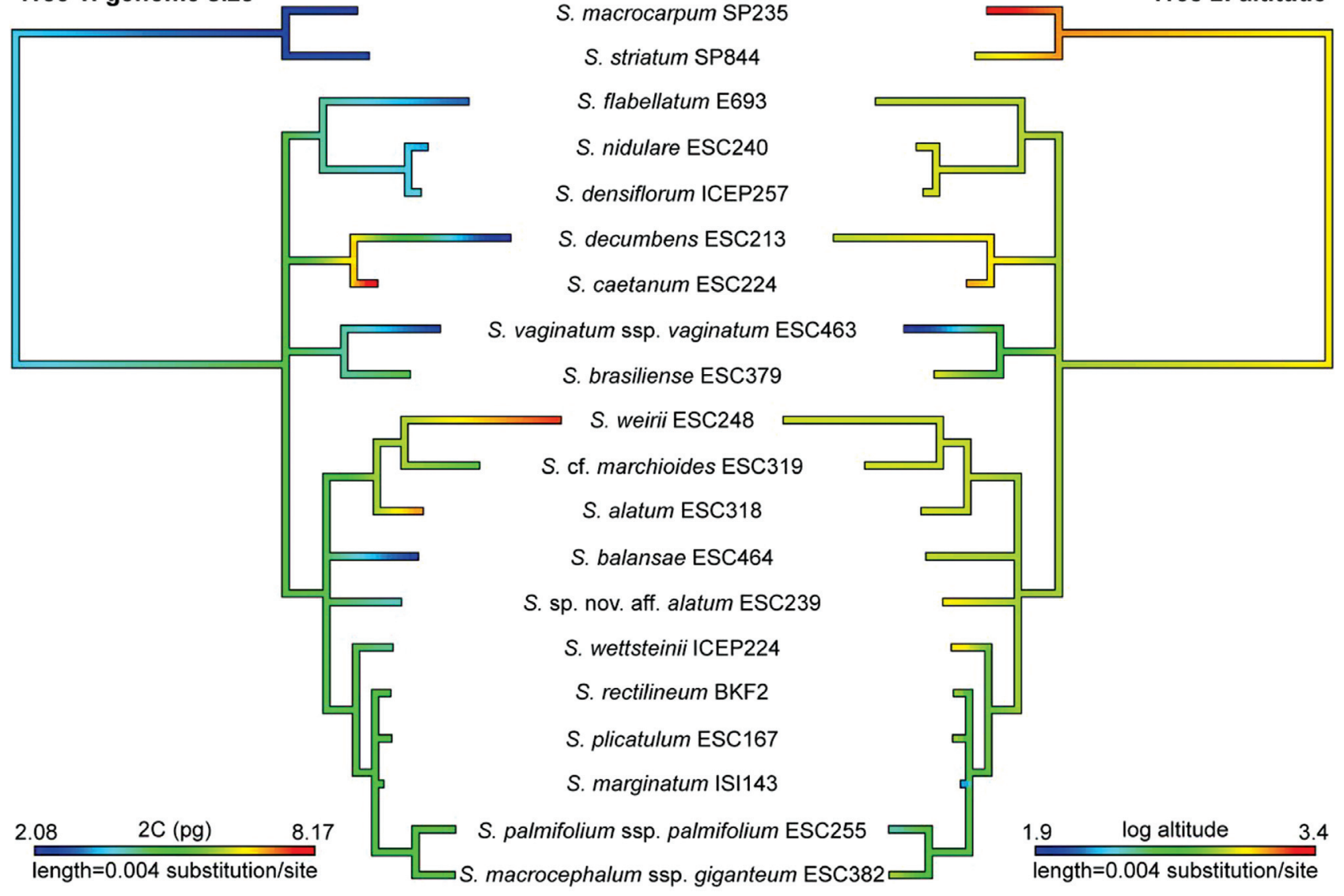

Figure 6 - Mirror trees showing maximum likelihood ancestral state reconstructions of DNA content (2C) on Tree 1 and natural log of altitude on Tree 2. Optimizations of continuous characters were performed with the contMap command of Phytools in R. Branch lengths are proportional to the number of molecular substitutions per site.

stable behavior was also reported for S. micranthum, in both diploids and polyploids (Tacuatiá et al., 2012) and for other Sisyrinchium species that were considered interspecific hybrids that underwent genome stabilization (Henderson, 1976; Cholewa and Henderson, 1984). The diploid Sisyrinchium sp. nov. aff. alatum was the only species with very low pollen viability $(22.70 \%)$, and in this case a putative hybrid status cannot be ruled out. More morphological and cytological studies are necessary to confirm this assumption.

Significant differences on pollen size were found among cytotypes of S. micranthum (Tacuatiá et al., 2012), where hexaploids $(2 n=48)$ presented pollen grains significantly bigger than those of diploids $(2 n=16)$. In the present work, although there was no apparent correlation between 2C DNA contents and pollen grain size, polyploid species have some of the largest pollen grains and also the highest 2C DNA contents (Tables 2 and 3).

\section{Concluding remarks}

This study reports the first attempts to understand patterns underlying karyotype and genome evolution in Sisyrinchium, sect. Viperella. Despite the stability in base chromosome number $(x=9)$, evolutionary changes in karyotypes of this section involve primarily variation in DNA amount, regardless of ploidy level, and secondly, polyploidy and variation in chromosome size. Although polyploidy and disploidy are considered important factors in the evolution of South American Iridaceae, in Sisyrinchium sect. Viperella polyploids they are less frequent, and disploidy changes were not reported. By raising mostly novel cytological data and analyzing them in a phylogenetic context, we suggest six transitions toward a genome size increase for the taxa of sect. Viperella that were originated from mechanisms other than polyploidy.

\section{Acknowledgments}

The authors acknowledge financial support from Conselho Nacional de Desenvolvimento Científico e Tecnológico (CNPq), grant numbers 477533/2009-4, 
503127/2010-8 and 478588/2011-9) and CAPES/COFECUB (French/Brazilian cooperation project Sv550/07).

\section{References}

Alexander MP (1980) A versatile stain for pollen fungi, yeast and bacteria. Stain Technol 55:13-18.

Alves LIF, Lima SAA and Felix LP (2011) Chromosome characterization and variability in some Iridaceae from Northeastern Brazil. Genet Mol Biol 34:259-267.

APG IV (2016) An update of the Angiosperm Phylogeny Group classification for the orders and families of flowering plants: APG IV. Bot J Linn Soc 181:1-20.

Bennetzen JL, Ma J and Devos KM (2005) Mechanisms of recent genome size variation in flowering plants. Ann Bot 95:127-132.

Charlesworth B, Sniegowski P and Stephan W (1994) The evolutionary dynamics of repetitive DNA in eukaryotes. Nature 371:215-220.

Chauveau O, Eggers L, Raquin C, Silvério A, Brown S, Couloux A, Cruaud C, Kaltchuk-Santos E, Yockteng R, Souza-Chies TT, et al. (2011) Evolution of oil-producing trichomes in Sisyrinchium (Iridaceae): insights from the first comprehensive phylogenetic analysis of the genus. Ann Bot 107:1287-1312.

Chauveau O, Eggers L, Souza-Chies TT and Nadot S (2012) Oil-producing flower within the Iridoideae (Iridaceae): Evolutionary trends in the flower of the New World genera. Ann Bot 110:713-729.

Cholewa AF and Henderson DM (1984) Biosystematics of Sisyrinchium section Bermudiana (Iridaceae) of the Rocky Mountains. Brittonia 36:342-363.

De Tullio L, Roitman G and Bernardello G (2008) Tamia (Iridaceae), a synonym of Calydorea: cytological and morphological evidence. Syst Bot 33:509-513.

Dolezel J, Bartos J, Voglmayr H and Greilhuber J (2003) Nuclear DNA content and genome size of trout and human. Cytometry A 51A:127-128.

Doyle JJ and Doyle JL (1990) A rapid total DNA preparation procedure for fresh plant tissue. Focus 12:13-15.

Erdtman G (1971) Pollen Morphology and Plant Taxonomy: Angiosperms: An Introduction to Palynology. Hafner Publishing Company, New York, 553 pp.

Escudero M, Martín-Bravo S, Mayrose I, Fernández-Mazuecos M, Fiz-Palacios O, Hipp AL, Pimentel M, Jiménez-Mejías P, Valvárcel M, Vargas P, et al. (2014) Karyotypic changes through dysploidy persist longer over evolutionary time than polyploid changes. PloS One 9:e85266.

Fachinetto J, Kaltchuk-Santos E, Inácio CD, Eggers L and Souza-Chies TT (2018) Multidisciplinary approaches for species delimitation in Sisyrinchium (Iridaceae). Plant Species Biol 33:3-15.

Felsenstein J (1985) Phylogenies and the comparative method. Am Nat 125:1-15.

Galbraith DW, Harkins KR, Maddox JM, Ayres NM, Sharma DP and Firoozabady E (1983) Rapid flow cytometric analysis of the cell cycle in intact plant tissues. Science 220:1049-1051.

Goldblatt P and Manning JC (2008) The Iris Family: Natural History and Evolution. Timber Press, Portland, $336 \mathrm{pp}$.

Goldblatt P and Takei M (1997) Chromosome cytology of Iridaceae - patterns of variation, determination of ancestral base numbers, and modes of karyotype change. Ann Mo Bot Gard 84:285-304.

Goldblatt P, Walbot W and Zimmer EA (1984) Estimation of genome size (C-value) in Iridaceae by cytophotometry. Ann Mo Bot Gard 71:176-180.

Greilhuber J, Dolezel J, Martin A. Lysák MA and Bennett M (2005) The origin, evolution and proposed stabilisation of the terms 'genome size' and 'C-value' to describe nuclear DNA contents. Ann Bot 95:255-260.

Hansen TF (1997) Stabilizing selection and the comparative analysis of adaptation. Evolution 51:1341-1351.

Henderson DM (1976) A biosystematic study of Pacific Northwestern blue-eyed grasses (Sisyrinchium, Iridaceae). Brittonia 28:149-176.

Katoh K and Standley DM (2013) MAFFT Multiple Sequence Alignment Software version 7: improvements in performance and usability. Mol Biol Evol 30:772-780.

Kenton A and Heywood CA (1984) Cytological studies in South American Iridaceae. Plant Syst Evol 146:87-104.

Kenton AY, Rudall PJ and Johnson AR (1986) Genome size variation in Sisyrinchium L. (Iridaceae) and its relationship to phenotype and habitat. Bot Gaz 147:342-345.

Koehler S, Cabral JS, Whitten WM, Williams NH, Singer RB, Neubig KM, Guerra M, Souza AP and Amaral MCE (2008) Molecular phylogeny of the neotropical genus Christensonella (Orchidaceae, Maxillariinae): species delimitation and insights into chromosome evolution. Ann Bot 102:491-507.

Leitch IJ and Bennett MD (2004) Genome downsizing in polyploid plants. Biol J Linn Soc 82:651-663.

Leitch AR and Leitch IJ (2012) Ecological and genetic factors linked to contrasting genome dynamics in seed plants. New Phytol 194:629-646.

Leitch IJ, Soltis DE, Soltis PS and Bennett MD (2005) Evolution of DNA amounts across land plants (embryophyta). Ann Bot 95:207-217.

Lepers-Andrzejewski S, Siljak-Yakovlev S, Brown SC, Wong M and Dron M (2011) Diversity and dynamics of plant genome size: An example of polysomaty from a cytogenetic study of Tahitian vanilla (Vanilla $\times$ tahitensis, Orchidaceae). Am J Bot 98:986-997.

Marie D and Brown SC (1993) A cytometric exercise in plant DNA histograms, with $2 \mathrm{C}$ values for 70 species. Cell 78:41-51.

Miller MA, Pfeiffer W and Schwartz T (2010) Creating the CIPRES Science Gateway for inference of large phylogenetic trees. In: Proceedings of the Gateway Computing Environments Workshop (GCE), 14 Nov. 2010, New Orleans, pp $1-8$.

Moraes AP, Leitch IJ and Leitch AR (2012) Chromosome studies in Orchidaceae: Karyotype divergence in Neotropical genera in subtribe Maxillariinae. Bot J Linn Soc 170:29-39.

Moraes AP, Souza-Chies TT, Stiehl-Alves EM, Burchardt P, Eggers L, Siljak-Yakovlev S, Brown SC, Chauveau O, Nadot S, Bourge M, et al. (2015) Evolutionary trends in Iridaceae: New cytogenetic findings from the New World. Bot J Linn Soc 177:27-49.

Müller K (2005) SeqState - primer design and sequence statistics for phylogenetic DNA data sets. Appl Bioinformatics 4:65-69.

Pagel M (1997) Inferring evolutionary processes from phylogenies. Zoologica Scripta 26:331-348. 
Pagel M (1999) The maximum likelihood approach to reconstructing ancestral character states of discrete characters on phylogenies. Syst Biol 48:612-622.

Pellicer J, Garcia S, Canela MÁ, Garnatje T, Korobkov AA, Twibell JD and Vallès J (2010) Genome size dynamics in Artemisia L. (Asteraceae): following the track of polyploidy. Plant Biol 12:820-830.

Peruzzi L, Leitch IJ and Caparelli KF (2009) Chromosome diversity and evolution in Liliaceae. Ann Bot 103:459-475.

Pinheiro J, Bates D, Debroy S, Sarkar D and R Core Team (2017) nlme: Linear and nonlinear mixed effects models. R package version 3.1-131. CRAN.R-project.org/package=nlme.

Ravenna PF (2000) Revisional studies in the genus Sisyrinchium VI. Onira, Bot Leaflets 5:13-19.

Ravenna PF (2002) Revisional studies in the genus Sisyrinchium IX. Onira, Bot Leaflets 7:20-41.

R Core Team (2017) R: A language and environment for statistical computing. R Foundation for Statistical Computing, Vienna, Austria. www.R-project.org.

Revell LJ (2012) Phytools: An R package for phylogenetic comparative biology (and other things). Methods Ecol Evol 3:217-223.

Ronquist F, Teslenko M, van der Mark P, Ayres DL, Darling A, Höhna S, Larget B, Liu L, Suchard MA and Huelsenbeck JP (2012) MrBayes 3.2: Efficient Bayesian phylogenetic inference and model choice across a large model space. Syst Biol 61:539-542.

Rudall P, Kenton AY and Lawrence TJ (1986) An anatomical and chromosomal investigation of Sisyrinchium and allied genera. Bot Gaz 147:466-477.

Schluter D, Price T, Mooers AO and Ludwig D (1997) Likelihood of ancestor states in adaptive radiation. Evolution 51:1699-1711.

Simmons MP, Müller K and Norton AP (2007) The relative performance of indel-coding methods in simulations. Mol Phylogenet Evol 44:724-740.

Souza-Chies TT, Santos EK, Eggers L, Flores AM, Stiehl-Alves EM, Fachinetto J, Lustosa J, Corrêa LB, Tacuatiá LO, Piccoli P, et al. (2012) Studies on diversity and evolution of Iridaceae species in southern Brazil. Genet Mol Biol 35:1027-1035.

Stamatakis A (2014) RAxML version 8: A tool for phylogenetic analysis and post-analysis of large phylogenies. Bioinformatics 30:312-1313.

Stiehl-Alves EM, Flores AM, Silverio A, Heck J, Eggers L, Kaltchuk-Santos E, Mariath JEA and Souza-Chies TT (2016) Differentiation between two self-compatible cytotypes of Herbertia lahue (Iridaceae): evidence from genotypic and phenotypic variation. Plant Syst Evol 302:669-682.

Suda J, Krahulcová A, Trávnícek P, Rosenbaumová R, Peckert T and Krahulec F (2007) Genome size variation and species relationships in Hieracium sub-genus Pilosella (Asteraceae) as inferred by flow cytometry. Ann Bot 100:1323-1335.

Tacuatiá LO, Souza-Chies TT, Flores AM, Eggers L, SiljakYakovlev S and Kaltchuk-Santos E (2012) Cytogenetic and molecular characterization of morphologically variable Sisyrinchium micranthum (Iridaceae) in southern Brazil. Bot J Linn Soc 169:350-364.

Tacuatiá LO, Kaltchuk-Santos E, Souza-Chies TT, Eggers L, Forni-Martins ER, Pustahija F, Robin O and Siljak-Yakovlev S (2016) Physical mapping of 35S rRNA genes and genome size variation in polyploid series of Sisyrinchium micranthum and S. rosulatum (Iridaceae: Iridoideae). Plant Biosyst 151:403-413.

Tamura K, Stecher G, Peterson D, Filipski A and Kumar S (2013) MEGA6: Molecular Evolutionary Genetics Analysis version 6.0. Mol Biol Evol 30:2725-2729.

\section{Internet Resources}

Bennett MD and Leitch IJ (2012) Plant DNA Cvalues database (Release 6.0, Dec. 2012). Available: http://www.rbgkew.org.uk/cval/database1.html (accessed December 2016).

Maddison WP and Maddison DR (2016) Mesquite: A modular system for evolutionary analysis. Version 3.10, distributed by the authors: http://mesquiteproject.org.

Nylander JAA (2004) MrModeltest v2. Program distributed by the author. Evolutionary Biology Centre, Uppsala University. https:/github.com/nylander/MrModeltest2 (accessed 20 Jul 2016).

Orme D, Freckleton R, Thomas G, Petzoldt T, Fritz S, Isaac N and Pearse W (2013) Package "caper": comparative analyses of phylogenetics and evolution in $\mathrm{R}$. http://cran.r-project.org/package=caper (accessed 19 Jul 2017).

\section{Supplementary material}

The following online material is available for this article: Table S1: Data of meiotic behaviour and meiotic index. Table S2: Dataset partitions for Maximum Likelihood (ML) and Bayesian Inference (BI) analyses.

Figure S1: Cluster analysis by Centroid Linkage method grouping taxa according to $2 \mathrm{C}$ genome size.

\section{Associate Editor: Loreta B. Freitas}

License information: This is an open-access article distributed under the terms of the Creative Commons Attribution License (type CC-BY), which permits unrestricted use, distribution and reproduction in any medium, provided the original article is properly cited. 